\title{
ASH2L drives proliferation and sensitivity to bleomycin and other genotoxins in Hodgkin's lymphoma and testicular cancer cells
}

\author{
Daniel Constantin ${ }^{1}$ and Christian Widmann (1)
}

\begin{abstract}
It is of clinical importance to identify biomarkers predicting the efficacy of DNA damaging drugs (genotoxins) so that nonresponders are not unduly exposed to the deleterious effects of otherwise inefficient drugs. Here, we initially focused on the bleomycin genotoxin because of the limited information about the genes implicated in the sensitivity or resistance to this compound. Using a whole-genome CRISPR/Cas9 gene knockout approach, we identified ASH2L, a core component of the H3K4 methyl transferase complex, as a protein required for bleomycin sensitivity in L1236 Hodgkin lymphoma. Knocking down ASH2L in these cells and in the NT2D1 testicular cancer cell line rendered them resistant to bleomycin, etoposide, and cisplatin but did not affect their sensitivity toward ATM or ATR inhibitors. ASH2L knockdown decreased cell proliferation and facilitated DNA repair via homologous recombination and nonhomologous end-joining mechanisms. Data from the Tumor Cancer Genome Atlas indicate that patients with testicular cancer carrying alterations in the ASH2L gene are more likely to relapse than patients with unaltered ASH2L genes. The cell models we have used are derived from cancers currently treated either partially (Hodgkin's lymphoma), or entirely (testicular cancer) with genotoxins. For such cancers, ASH2L levels could be used as a biomarker to predict the response to genotoxins. In situations where tumors are expressing low levels of ASH2L, which may allow them to resist genotoxic treatment, the use of ATR or ATM inhibitors may be more efficacious as our data indicate that ASH2L knockdown does not affect sensitivity to these inhibitors.
\end{abstract}

\section{Introduction}

Cancer is the second leading cause of death worldwide, only surpassed by cardiovascular disease ${ }^{1}$. In high income countries however, cancer is responsible for nearly twice as many deaths as cardiovascular disease, with a global trend toward cancer becoming the leading cause of death worldwide ${ }^{2}$. One of the main anticancer therapeutic avenues are represented by DNA damaging agents (also called genotoxins) ${ }^{3}$. The anticancer properties of these drugs were discovered in the 1940s. Genotoxins became very popular in the 1960s and $1970 \mathrm{~s}^{4}$. To this day, DNA damage causing agents are the largest class of anticancer

Correspondence: Christian Widmann (Christian.Widmann@unil.ch)

'Department of Biomedical Sciences, University of Lausanne, Bugnon 7, 1005 Lausanne, Switzerland

Edited by J.-E. Ricci drugs. They are used to treat lung, breast, bladder, stomach, ovarian, testicular, and other cancers ${ }^{5}$. These genotoxic agents work by activating an intricate series of signaling pathways that, taken together, have been termed the DNA damage response (DDR). In eukaryotes, the DDR involves a tightly regulated series of transcriptional, post-transcriptional and post-translational events that have evolved to prevent transmission of damaged DNA to daughter cells. Initially the cell cycle is stopped and the DNA repair machinery is recruited to DNA lesions. If the extent of DNA damage surpasses the cell's DNA repair abilities, additional pathways are activated that lead to cell death via mitotic catastrophe, apoptosis or necrosis, the ultimate outcome that is expected from genotoxins ${ }^{6-8}$. Although these types of chemotherapy agents are used in many standard therapy regimens that represent the gold

\section{(c) The Author(s) 2021, corrected publication 2021}

(c) (i) Open Access This article is licensed under a Creative Commons Attribution 4.0 International License, which permits use, sharing, adaptation, distribution and reproduction c. in any medium or format, as long as you give appropriate credit to the original author(s) and the source, provide a link to the Creative Commons license, and indicate if changes were made. The images or other third party material in this article are included in the article's Creative Commons license, unless indicated otherwise in a credit line to the material. If material is not included in the article's Creative Commons license and your intended use is not permitted by statutory regulation or exceeds the permitted use, you will need to obtain permission directly from the copyright holder. To view a copy of this license, visit http://creativecommons.org/licenses/by/4.0/. 
standard of care at the moment, they are also highly unspecific and almost always display systemic side effects that can be life threatening .

Here, we have focused our initial investigation on a DNA damaging drug called bleomycin. This drug was discovered in the 1960s and FDA approved in 1973. It became very popular in oncology clinics due to its antitumor activity and low myelosuppressive properties ${ }^{10,11}$. Bleomycin is currently part of the gold standard therapy for Hodgkin's lymphoma (HL), testicular cancer (TC), germ cell cancers and others but its mechanism of action is still not fully understood ${ }^{12,13}$. Akin to other unspecific chemotherapy drugs, bleomycin has severe side effects, mainly pulmonary toxicity that can be lethal on its own. Up to $46 \%$ of patients treated with bleomycin containing therapies develop pulmonary complications ${ }^{14}$. These complications can lead to the patient's death in $1-4 \%$ of cases $^{15-18}$. We focused on this drug because of a knowledge gap between the wide use of bleomycin in the clinic and the limited information about the genes implicated in the sensitivity or resistance to this compound. Here we show that HL and TC cancer cells depleted of ASH2L (Absent, Small, or Homeotic-Like 2) are more resistant to bleomycin and other DNA damaging agents. ASH2L is part of protein complexes responsible for the trimethylation of histone 3 at lysine 4 (H3K4me3). These complexes are comprised of a catalytic subunit (either MLL1, MLL2, MLL3, MLL4, hSET1A, or hSET1B) bound to the integral core members of the complex (ASH2L, RbBP5, WDR5, and DPY30) ${ }^{19}$. H3K4me3 is found mainly at promoters of transcriptionally active genes. Some promoters are marked by both $\mathrm{H} 3 \mathrm{~K} 4 \mathrm{me} 3$, considered an activation mark, and H3K27me3, considered a suppressive mark. Although typically not expressed, these promoters have been termed bivalent promoters, and were proposed to be "poised" for rapid activation and deactivation of gene expression ${ }^{20}$. Bivalent promoters have been reported mainly in embryonic stem cells, and the genes downstream of them are important in differentiation and development ${ }^{21,22}$. Interestingly, bleomycin resistance in ASH2L knockdown cells does not seem to be mediated through changes in the gene expression, but rather through a global decrease in H3K4me3 levels that prime the chromatin for DNA repair. Within the context of personalized cancer therapy, decreased ASH2L levels could be used as a biomarker for predicting a poor response to DNA damaging agent-based therapy.

\section{Results}

We conducted a whole genome CRISPR/Cas9 gene knockout screen ${ }^{23,24}$ in the presence or in the absence of bleomycin in L1236 HL cells. These cells are derived from a type of cancer that is currently treated with bleomycincontaining chemotherapy. MaGECK algorithm ${ }^{25}$ analysis of our CRISPR/Cas9 screen showed that ASH2L-depleted cells were enriched in the bleomycin-treated population (Fig. 1a, Table S1). All six sgRNAs targeting ASH2L present in our library were enriched in the population of cells treated for 10 days with bleomycin when compared to the untreated population cultured for the same period of time (Fig. S1A). ASH2L mouse knockouts are early embryonic lethal and the absence of ASH2L does not allow embryonic stem cell survival. Heterozygote mice present no abnormal phenotypes ${ }^{26}$. Blastocyst formation proceeds apparently normally in the absence of ASH2L but further development does not take place ${ }^{26}$. Invalidation of ASH2L, or its binding partner DPY30, blocks proliferation and differentiation in the hematopoietic lineage $\mathrm{e}^{27,28}$. The tolerance to ASH2L gene disruption seems therefore to vary between cell types. If L1236 cells tolerate a complete absence of $\mathrm{ASH} 2 \mathrm{~L}$, recovery of ASH2L-specific sgRNAs in the CRISPR/Cas9 screen could have come from full knockout cells or from cells in which only one ASH2L allele was disrupted. If L1236 cannot proliferate/survive in the absence of ASH2L, the recovery of ASH2L-specific sgRNAs likely originated from cells that still expressed some functional ASH2L as a result of only one allele being disrupted or through non frameshift mutations preserving some of the activity of the protein.

In order to validate the results of the CRISPR/ Cas9 screen, we used an independent genetic approach based on small hairpin RNAs (shRNAs) to investigate the effect of ASH2L depletion on genotoxin-resistance. The shRNA-mediated decrease in ASH2L protein levels in L1236 cells was accompanied by H3K4 methylation reduction (Fig. 1b). Although the most commonly expressed ASH2L isoform has a theoretical molecular weight of $60.2 \mathrm{kDa}$ (NM_001105214.2), this protein is commonly detected at $80 \mathrm{kDa}^{29,30}$, possibly due to posttranslational modifications. ASH2L knockdown in L1236 cells resulted in increased survival in response to bleomycin and to another genotoxin, etoposide, a topoisomerase II inhibitor (Fig. 1c-e).

In the absence of bleomycin exposure, the mere culture for 10 days of the cell population expressing the sgRNA library led to a decrease in abundance of ASH2L-targeting sgRNAs (Fig. S1B). ASH2L-targeting sgRNAs were among the top most depleted ones following a 10-day culture period (Fig. S1C). This indicates that, in untreated cells, the absence of ASH2L decreases the ability of the cell population to expand, for example because of a reduced proliferation potential. A decrease in cell proliferation upon ASH2L depletion was indeed previously reported ${ }^{31}$. We could reproduce the negative impact of ASH2L loss on population growth using shRNA-mediated ASH2L knockdown (Fig. 1f). Cells lacking ASH2L had a decreased proliferation potential (Fig. 1g), indicating that the 


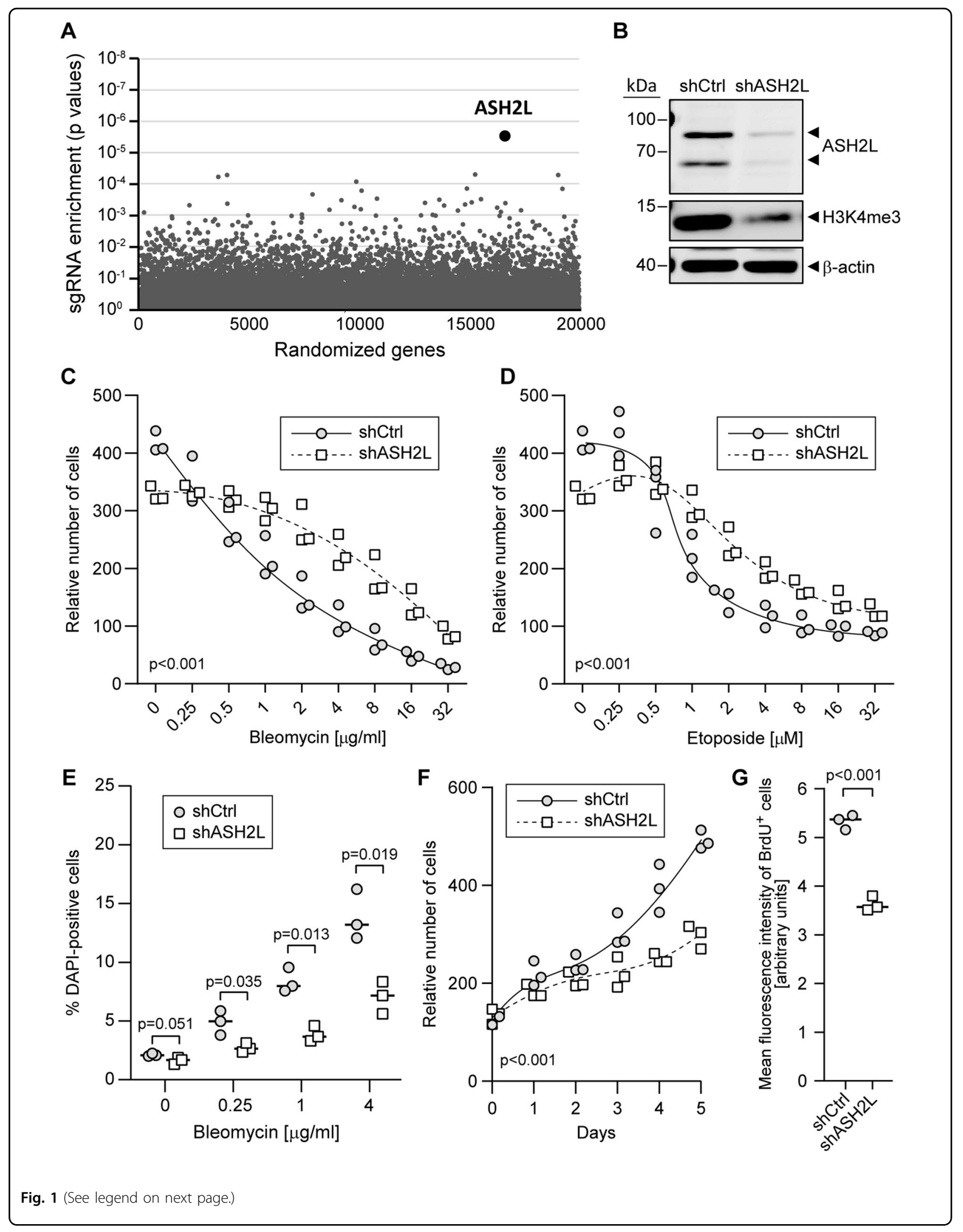


(see figure on previous page)

Fig. 1 ASH2L depletion leads to resistance to genotoxins in Hodgkin's lymphoma cells. A MaGECK-based sgRNA enrichment analysis of the CRISPR/Cas9 whole-genome knockout screen results. The graph depicts the $p$ value associated with the observed difference in sgRNA abundance between untreated cells and cells treated with bleomycin $(250 \mathrm{ng} / \mathrm{ml})$ for 10 days. B Western blot depicting shRNA-mediated knockdown of ASH2L and $\mathrm{H} 3 \mathrm{~K} 4 \mathrm{me} 3$ levels. The arrowheads indicate the $2 \mathrm{ASH} 2 \mathrm{~L}$ splice variants expressed in most tissues ${ }^{91}$. C, D Control (shCtrl) and ASH2L knockdown (shASH2L) L1236 cells were treated with increasing concentrations of bleomycin (panel C) or etoposide (panel $\mathbf{D}$ ) for 3 days. The relative numbers of cells in the wells were estimated by Presto-Blue assays. E ASH2L knockdown and control cells were treated with the indicated concentrations of bleomycin for $72 \mathrm{~h}$. The dead cells were stained with DAPI and then analyzed by flow cytometry. F ASH2L knockdown and control cells were plated in 96-well plates and the relative number of cells was analyzed each day during 5 days. G Flow cytometry analysis of the DNA synthesis rate, measured by BrdU pulse labeling, in control (shCtrl) and ASH2L knockdown (shASH2L) cells.

reduced population growth upon ASH2L silencing is, at least partly, a consequence of decreased proliferation. Regarding the cell cycle profile, ASH2L depleted L1236 cells displayed a slight decrease in the percentage of cells in S-phase, and an increase in the percentage of cells blocked in S-phase. Upon bleomycin treatment, there were almost no cell cycle differences between control and ASH2L knockdown cells (Fig. S1D).

Interestingly, none of the other genes that were detected as important for optimal population growth (e.g., PFN1, PPP4C, DUT, or RPLP0) (Fig. S1C) had the corresponding sgRNAs significantly enriched in the bleomycin-treated population (Table S2). This indicates that decreased proliferation is not the main mechanism driving the observed resistance to bleomycin upon ASH2L depletion.

One possibility that could explain the observed bleomycin-resistance phenotype is that a decrease in the H3K4me3 mark, which labels transcriptionally "open" chromatin, results in higher proportion of heterochromatin within the nucleus. This would make it more difficult for bleomycin to access DNA and cause double strand breaks. However, the levels of H3K9me3 and H3K27me3, the main heterochromatin markers ${ }^{32}$, were not changed upon ASH2L knockdown in L1236 cells (Fig. S2A, B).

We also checked if overexpression of ASH2L had an impact on L1236 cell survival upon genotoxin exposure or on H3K4me3 levels but found none (Fig. S2D).

As stated above, H3K4me3 modification, which mainly occurs on promoters, is considered a mark of transcriptionally active open chromatin ${ }^{32}$. At first sight, it was surprising that a protein required for this modification ended up to be the top hit in a screen designed to identify proteins modulating bleomycin sensitivity. While most publications are focusing on H3K4me3 in the context of transcription, there is evidence that this mark influences the DNA repair ability of cells. Firstly, upon DNA break induction, histone lysine demethylases are recruited to damaged chromatin to remove the H3K4me3 mark ${ }^{33-35}$. Secondly, Bayo et al. have elegantly shown that augmenting H3K4me3 levels in cancer cells decreases their ability to repair DNA breaks efficiently, rendering cells more sensitive to DNA damaging agents ${ }^{36}$. These studies prompted us to investigate the cells' ability to repair their DNA upon ASH2L depletion. We used specifically engineered U2OS cells that carry reporters for the two main DNA repair pathways in mammalian cells: the DR-GFP reporter, developed by Maria $\operatorname{Jasin}^{37}$, which measures repair through homologous recombination (HR), and the EJ5-GFP reporter, developed by Jeremy stark ${ }^{38}$, which measures repair through nonhomologous end joining (NHEJ). Figure 2a depicts how the reporters record these two types of DNA repair. ASH2L knockdown and reduction in H3K4me3 levels was achieved by transfecting the two reporter cell lines with a pool of 30 ASH2Ldirected siRNAs (Fig. 2b). Upon induction of DNA damage by I-SceI expression in the reporter cells lines, we observed a slight but significant increase in both HR and NHEJ repair efficiencies upon ASH2L silencing (Fig. 2c). In accordance with the hypothesis that ASH2L is detrimental to DNA repair, endogenous ASH2L proteins were found to be excluded from areas of laser-damaged DNA (Fig. 2d and Fig. S2C).

We then tested if increased DNA repair activity is also detected in L1236 cells subjected to the selection conditions used in the CRISPR/Cas9 screen. Control and ASH2L-knockdown cells were therefore incubated with increasing bleomycin concentrations for one hour or for $48 \mathrm{~h}$ and the extent of DNA damage evaluated by measuring phosphorylated H2A.X ( $\gamma$ H2A.X) levels ${ }^{39}$. After $1 \mathrm{~h}$ of bleomycin treatment, $\gamma \mathrm{H} 2 \mathrm{~A} . \mathrm{X}$ levels were similar between control and ASH2L knockdown cells, indicating similar DNA damage induction in the two cell types. However, after $48 \mathrm{~h}$, these levels increased more in control cells compared to ASH2L knockdown cells (Fig. 2e), supporting the notion that, like in U2OS cells, depleting ASH2L in L1236 cells leads to increased DNA repair capability.

As stated above, ASH2L is part of a protein complex that is responsible for the methylation of histone 3 at lysine 4 . This chromatin modification is generally present at the promoters of active genes ${ }^{40}$. We investigated the possibility that knocking down ASH2L leads to a gene expression signature responsible for the promotion of 

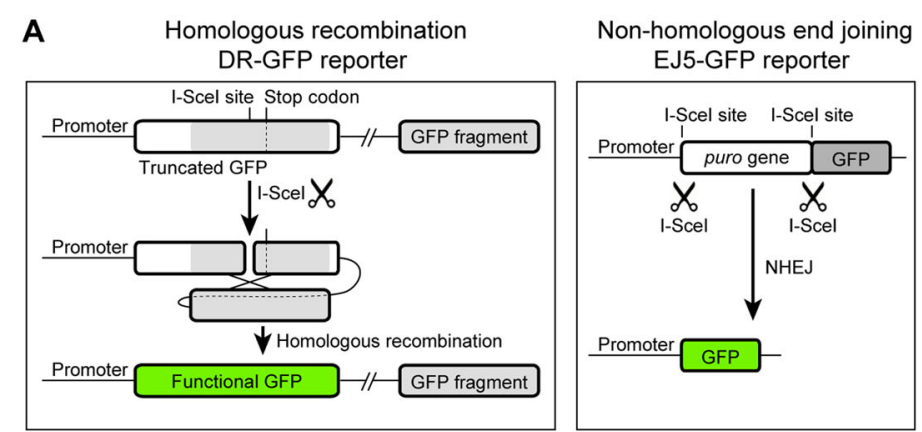

\section{B}

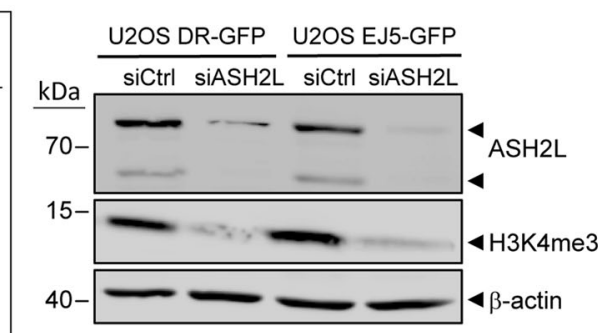

C
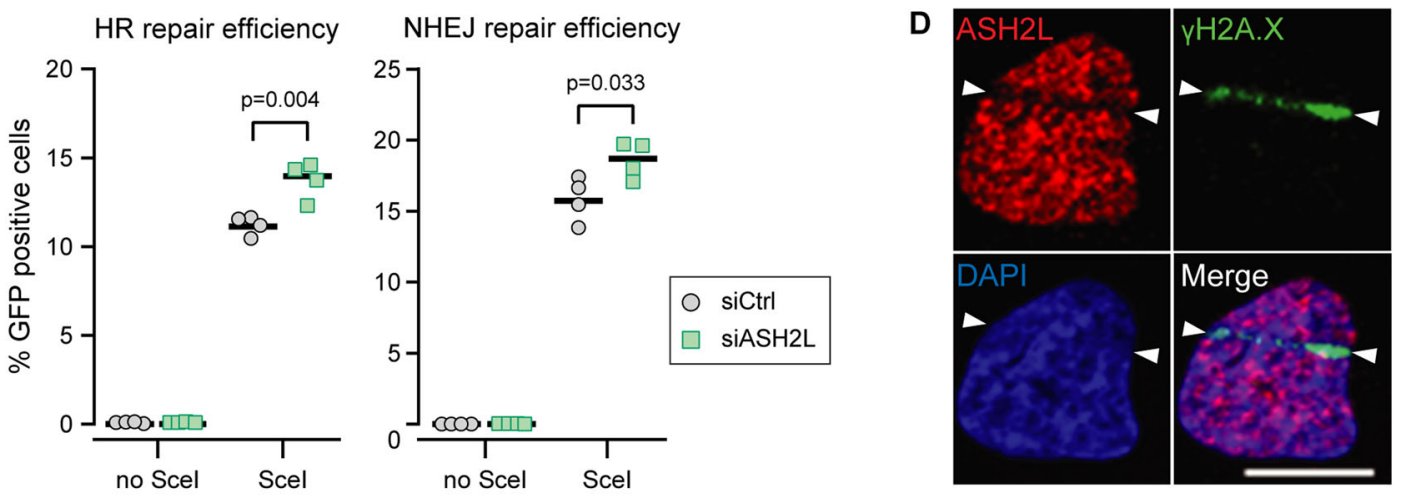

E

1 hour treatment
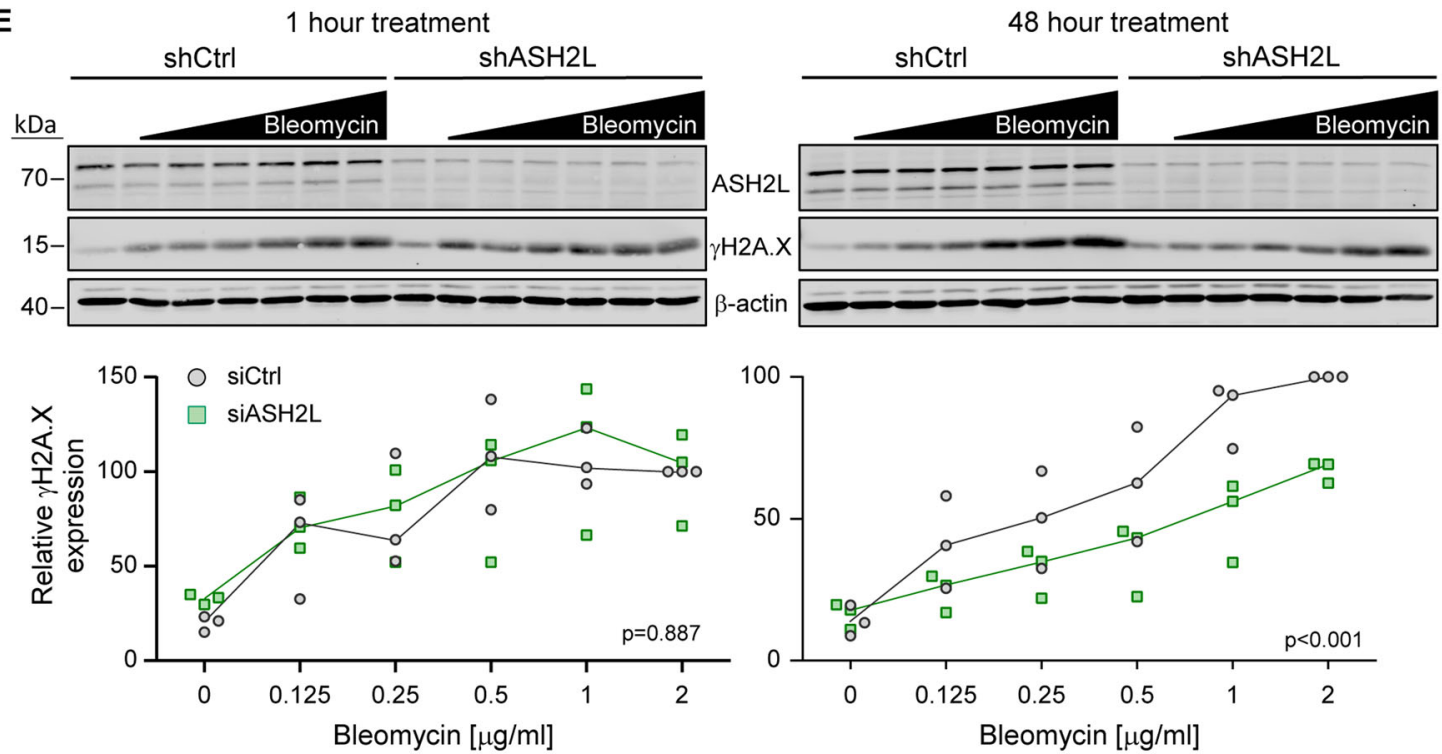

Fig. 2 (See legend on next page.)

DNA repair and resistance to genotoxic stress. There is some evidence that points in this direction as ASH2L interacts with $\mathrm{p} 53$ at the promoters of proapoptotic genes $^{41}$. Note, however, that the HL cell line in which we performed our screen is TP53 null ${ }^{42}$. We performed three independent transcriptomic analyses of control (shCtrl) and ASH2L knockdown (shASH2L) L1236 cells. Upon setting a threshold of false discovery rate (FDR) of 0.05 and fold change $\geq 2$, we found 93 upregulated and 228 downregulated genes in cells in which ASH2L was silenced compared to the control cells. The differential expression analysis for 14,000 genes is provided in Table S3. The majority of the upregulated genes were low expressed genes (Fig. 3a). The top 40 upregulated genes 
(see figure on previous page)

Fig. 2 ASH2L depletion facilitates DNA repair. A Schematic representation (not to scale) of the DR-GFP reporter (left) and EJ5GFP reporter (right). The DR-GFP construct bears a cDNA encoding the full-length GFP that contains an I-Scel restriction site disrupting the reading frame and leading to a premature stop codon. This CDNA is followed by a $5^{\prime}$ - and $3^{\prime}$-truncated GFP fragment that does not contain the I-Scel restriction site. The sequences of this fragment and the complementary region in the full-length cDNA are indicated by different shades of gray. When cells expressing this reporter are transduced with a lentivirus encoding the I-Scel enzyme, the reporter is cleaved at the I-Scel site. The ensuing DNA repair by homologous recombination removes the termination codon in the full-length cDNA allowing for the production of a functional GFP (green). The EJ5GFP bears a puromycin resistance gene flanked by two I-Scel restriction sites. This gene is followed by a GFP-encoding CDNA. In cells expressing this reporter, removal of the puromycin resistance gene is achieved by transduction with an I-Scel encoding lentivirus. The ensuing NHEJ-mediated repair brings the promoter and the GFP CDNA close together, allowing for GFP production. B Western blot depicting siRNA-mediated ASH2L knockdown efficiency in the U2OS DR-GFP and U2OS EJ5GFP reporter cell lines and the resulting decrease in H3K4me3. C U2OS DR-GFP and U2OS EJ5GFP cells were transfected with control siRNAs or ASH2L-specific siRNAs for $48 \mathrm{~h}$ and then infected with an I-Scel endonuclease-carrying lentivirus. Forty-eight hours post infection, the percentage of GFP-positive cells was quantitated by flow cytometry (four independent experiments; the horizontal bars correspond to the medians). D Live U2OS wild-type cells were micro-irradiated using the laser of a confocal microscope. The cells were then fixed and stained with the indicated antibodies. Nuclei were labeled with DAPI. White arrowheads mark the boundaries of the irradiation track. Scale bar: $10 \mu \mathrm{m}$. E L1236 cells were treated with $0,0.06,0.12,0.25,0.5,1$, or $2 \mu \mathrm{g} / \mathrm{ml}$ of bleomycin. Samples were harvested $1 \mathrm{~h}$ (left) and $48 \mathrm{~h}$ (right) posttreatment. The cells were lysed and $7.5 \mu \mathrm{g}$ of proteins were analyzed by Western blotting using the indicated antibodies. The quantitation from three independent experiments are shown below the blots. The intensity of the $\mathrm{YH} 2 \mathrm{~A}$.X bands were normalized to the corresponding $\beta$-actin signals and then expressed as percentage of the value of control cells exposed to the highest concentration of bleomycin.

are shown in Fig. $3 \mathrm{~b}$ and the top 40 downregulated genes are shown in Fig. 3c. We performed a gene ontology (GO) analysis on the genes that were upregulated and downregulated (FDR $<0.05$ and fold change $\geq 2$ ). The main enriched GO term when analyzing the genes downregulated in the ASH2L knockdown cells was cell proliferation regulation (Fig. 3d). This is in agreement with the observation that these cells grow slower (Fig. 1f). No enriched GO terms were found when analyzing the genes that were upregulated upon ASH2L knockdown. These data indicate that resistance to bleomycin observed upon ASH2L depletion is not a consequence of increased expression of genes involved in DNA repair.

Since the resistance to genotoxins observed after ASH2L downregulation does not seem to be regulated through changes in the transcriptome, we sought other possible explanations. One possibility is that, upon DNA breaks being sensed, H3K4 demethylases are recruited to the lesion and remove this mark. Only then is the repair machinery recruited and the break repaired through $\mathrm{HR}$ or NHEJ. In recent years, a few studies have shown that hindering the cells' ability to remove the H3K4me3 mark at areas of DNA damage results in a decreased ability of cells to repair their DNA leading to subsequent sensitivity to genotoxins ${ }^{33,34,36}$. Our results are in agreement with these observations. We extend these findings by showing, for the first time, increased DNA repair capabilities of cells with diminished H3K4me3 and/or ASH2L levels. One way to test the hypothesis that low levels of H3K4me3 promote DNA repair is through overexpressing a histone lysine demethylase, such as KDM5 $\mathrm{A}^{43}$. Unfortunately, we were unable to obtain stable expression of KDM5A in cells using either retroviruses, inducible lentiviruses, or generation of stable cell lines through plasmid integration. We could obtain KDM5A expression by transfecting cells with KDM5A-expressing plasmids but for this we had to use five times the usual amounts of DNA during the transfection procedure (this "over" transfection was obtained using $5 \mu \mathrm{g}$ of DNA per well of 12 -well plates containing $10^{5}$ cells). This expression was functional, as evidenced by decreased levels of H3K4me3, but was very transient (Fig. S3).

Our data indicate that cells with reduced H3K4me3 levels have a selective advantage compared to normal cells in repairing their DNA in response to genotoxin-induced DNA breaks. This is in line with earlier studies showing that a reduced ability to remove the H3K4me3 mark at areas of DNA damage hampers the recruitment of repair proteins, leading to subsequent sensitivity to genotoxins $^{33,34,36}$. We can therefore predict that H3K4me3 levels no longer influence cell survival when cells are prevented from turning on the signals that bring DNA repair proteins to sites of damaged DNA. This can be achieved through inhibition of ATM or ATR, the two main DNA lesion signaling kinases ${ }^{44}$. In the absence of ATM or ATR, cells are blind to DNA damage and die from unrepaired DNA breaks, through mitotic catastrophe for exam$\mathrm{ple}^{45,46}$. Figure 4 shows indeed that ASH2L-depleted cells have no survival benefit when incubated with ATM or ATR inhibitors (i.e., their $\mathrm{IC}_{50}$ values are similar to those of the control cells).

We next focused on TC for which bleomycin is part of the standard therapy (bleomycin, etoposide, and cisplatin). TC represents around $2 \%$ of the total number of cancers in males and the most common malignancy in males aged 15-34 years. The incidence of TC has doubled in the past 40 years and continues to increase ${ }^{47,48}$. Due to the external location of the affected organs and the 
A

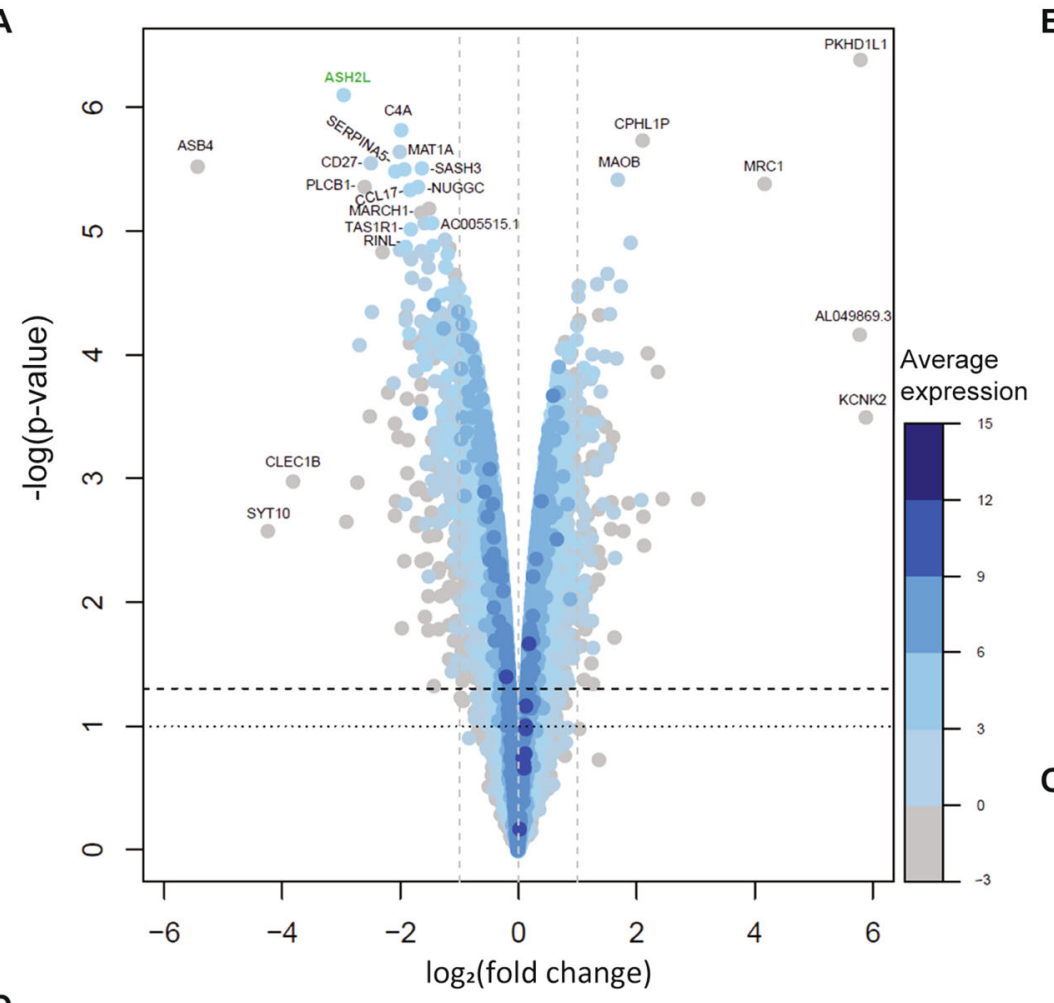

D

GO analysis of transcripts detected as down-regulated upon ASH2L knockdown

\begin{tabular}{|c|c|c|c|}
\hline Go biological process & $\begin{array}{c}\text { Fold } \\
\text { enrichment }\end{array}$ & $\begin{array}{c}\text { Raw P- } \\
\text { value }\end{array}$ & FDR \\
\hline regulation of cell population proliferation (GO:0042127) & 2.2 & $9.4 \mathrm{E}-06$ & $3.0 \mathrm{E}-02$ \\
\hline regulation of localization (GO:0032879) & 1.9 & $1.1 \mathrm{E}-06$ & $1.8 \mathrm{E}-02$ \\
\hline animal organ development (GO:0048513) & 1.8 & $7.6 \mathrm{E}-06$ & $3.0 \mathrm{E}-02$ \\
\hline anatomical structure development (GO:0048856) & 1.5 & $1.3 \mathrm{E}-05$ & $3.6 \mathrm{E}-02$ \\
\hline multicellular organismal process (GO:0032501) & 1.5 & $1.8 \mathrm{E}-06$ & $9.7 \mathrm{E}-02$ \\
\hline response to stimulus (GO:0050896) & 1.4 & $1.2 \mathrm{E}-06$ & $9.8 \mathrm{E}-02$ \\
\hline
\end{tabular}

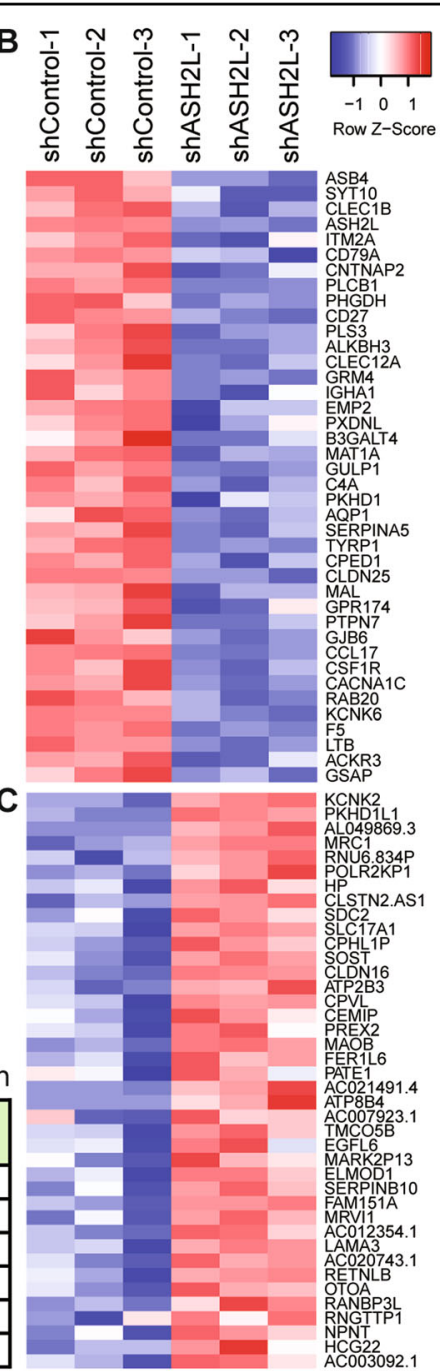

Fig. 3 Transcriptome changes upon ASH2L depletion in L1236 cells. A Volcano plot showing on the $x$-axis changes in gene expression levels and on the $y$-axis the $p$ values associated with these changes. The average expression of the genes is indicated by a color code (see scale bar on the right of the volcano plot). B, C Heatmaps depicting, according to fold changes, the top 40 downregulated (panel B) and upregulated genes (panel C) with FDRs $<0.05$. Each column represents one independent experiment. D Gene ontology (GO) analysis of genes downregulated upon ASH2L silencing (FDR $<0.05$ and fold change $\geq 2)$.

generally positive response to chemotherapy, TC has one of the highest cancer cure rates (approximately 95\%) ${ }^{49}$. Despite this high survival rate, there is a subset of patients with poor or even absence of response to standard chemotherapy ${ }^{50}$. There are currently no consensus biomarkers for predicting the effectiveness of the standard chemotherapy used to treat $\mathrm{TC}^{51}$. We transduced $\mathrm{TC}$ NT2D1 cells with either control shRNA or an shRNA targeting ASH2L and tested the effectiveness of the knockdown and the subsequent H3K4me3 decrease in these cells (Fig. 5a). Strikingly, ASH2L knockdown NT2D1 cells were resistant to three of the main drugs used in TC treatment (Fig. 5b). The observed resistance correlated with decreased DNA damage after $48 \mathrm{~h}$ of drug exposure, indicating more efficient repair of damaged DNA in ASH2L-depleted cells (Fig. 5c). Similarly to L1236 cells, overexpression of ASH2L in NT2D1 cells did not change their sensitivity to bleomycin (Fig. S2E). We also observed that NT2D1 cells were more sensitive to bleomycin than L1236 cells. Therefore, we compared the levels of ASH2L protein, in these two cell models. Interestingly, the more sensitive NT2D1 cells exhibited considerably higher levels of ASH2L than L1236 cells (Fig. S5), further supporting the notion that lower levels of ASH2L is associated with resistance to genotoxins ${ }^{41}$.

Due to the observed genotoxin resistance in ASH2L knockdown cells, we checked if the available clinical data support the idea that ASH2L levels represent a prognostic 


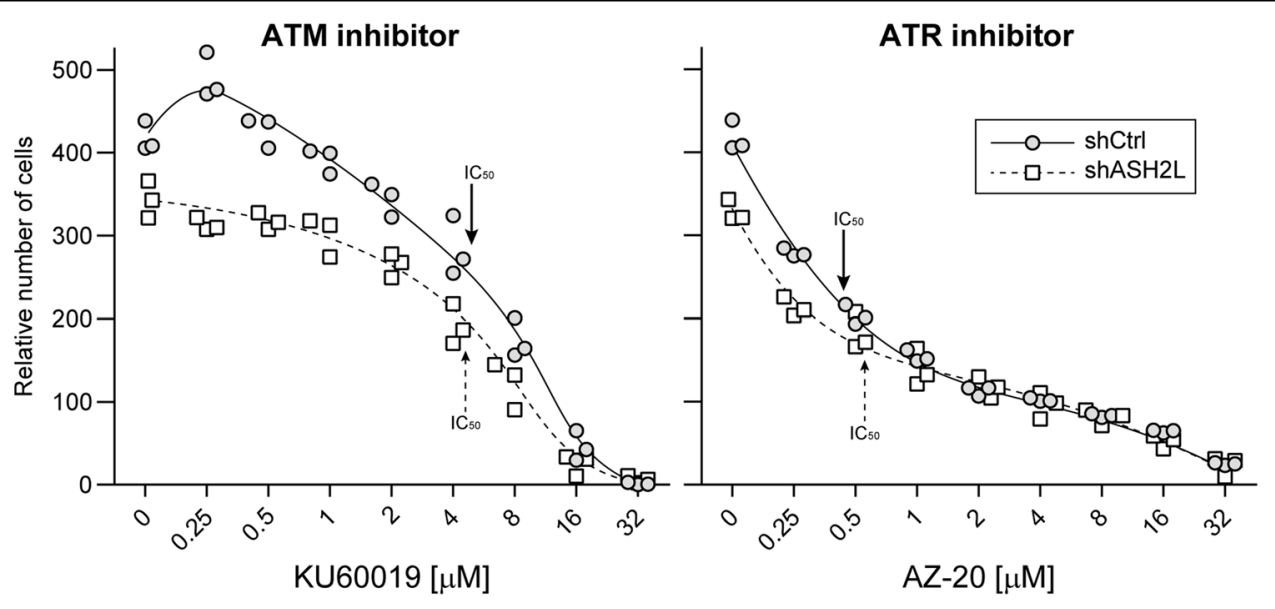

Fig. 4 Effect of ASH2L depletion on ATM or ATR inhibition-induced death. Control (shCtrl) and ASH2L-silenced (shASH2L) L1236 cells were incubated with increasing concentrations of the KU60019 ATM inhibitor or the AZ-20 ATR inhibitor for $72 \mathrm{~h}$. The numbers of cells in the wells were quantitated using the Presto-Blue assay. Three independent experiments were performed. The curves go through the median values. The functionality of KU60019 is shown in Fig. S4. IC 50 values correspond to the drug concentrations that intersect the curves halfway between the highest and lowest $y$-axis values.

marker in TC patients. Using the Tumor Cancer Genome Atlas (TCGA), available through the cBioportal website ${ }^{52}$, we found no impact of ASH2L alterations on overall cancer survival. However, TC patients carrying alterations in the ASH2L gene were significantly more likely to relapse, indicating that the first line of treatment was not effective (Fig. 5d). The alterations were of various types, one homozygous deletion, one missense mutation, and one gene amplification. Consistent with this last case, our results do not indicate that ASH2L overexpression impacts resistance to treatment (Fig. S2D-E). Interestingly, this patient presenting amplification of the ASH2L gene (patient ID: TCGA-2G-AAF6), also presented a KRAS G12V mutation, a mutation that is well-known to negatively impact overall cancer survival and relapse s3,54. $^{5}$. We hypothesize that the KRAS G12V mutation is the cause of relapse in this particular patient, and not the amplification of ASH2L gene. Unfortunately, this type of data is not yet available for HL samples, preventing us from testing whether ASH2L mutations are found associated with this disease. Lastly, we checked if there was any evidence of tumor samples that showed decreased levels of ASH2L gene expression. Using TCGA data analyzed through the GEPIA software ${ }^{55}$, we identified ASH2L as being overexpressed at the mRNA level in TC samples compared to normal tissues. Interestingly, some TC tumor samples presented very low levels of ASH2L mRNA, even below the levels detected in normal tissues (Fig. 5e). According to our hypothesis, the minority of patients with low ASH2L and/or H3K4me3 levels should be treated with non-DNA damage-based therapy in order for them not to suffer from the toxic side effects of noneffective genotoxic drugs.

\section{Discussion}

The idea that cancer genome data can be used to predict the response to therapy of an individual, and offer potential guidelines to an optimal type of treatment, has been postulated since the first sequencing of the human genome $^{56}$. This concept is supported by recent metaanalyses of biomarker-based approaches in clinical oncology showing significant improvement in efficacy and overall death reduction caused by chemotherapy toxicity when a personalized approach is used compared to a nonpersonalized one $\mathrm{e}^{57,58}$. Clinical oncologists generally agree that there is an urgent need for new biomarkers to predict the sensitivity or resistance to a particular treatment as this is a major limiting factor for contemporary precision medicine ${ }^{59}$. The results presented here indicate that patients with low levels of ASH2L or H3K4me3 are more likely to relapse when treated with DNA damaging chemotherapy.

Although the overwhelming majority of studies investigating H3K4me3 modification do so from the perspective of transcription ${ }^{19,32,60}$, some recent studies have focused on this modification in the context of DNA damage. Enzymes responsible for removing this mark, mainly members of the KDM5 family of proteins, are recruited to damaged DNA. Knockdown of these proteins decreases the ability of cells to repair their damaged DNA $^{33-35}$. Similarly, small molecule inhibitors of KDM5 enzymes increase the levels of H3K4me3 chromatin modification, which in turn leads to impaired DNA repair through both HR and nonhomologous end joining ${ }^{36,61}$. Our data are in agreement with these observations. We show that reducing the levels of H3K4me3 leads to increase in both of these repair pathways (Fig. S6). In 

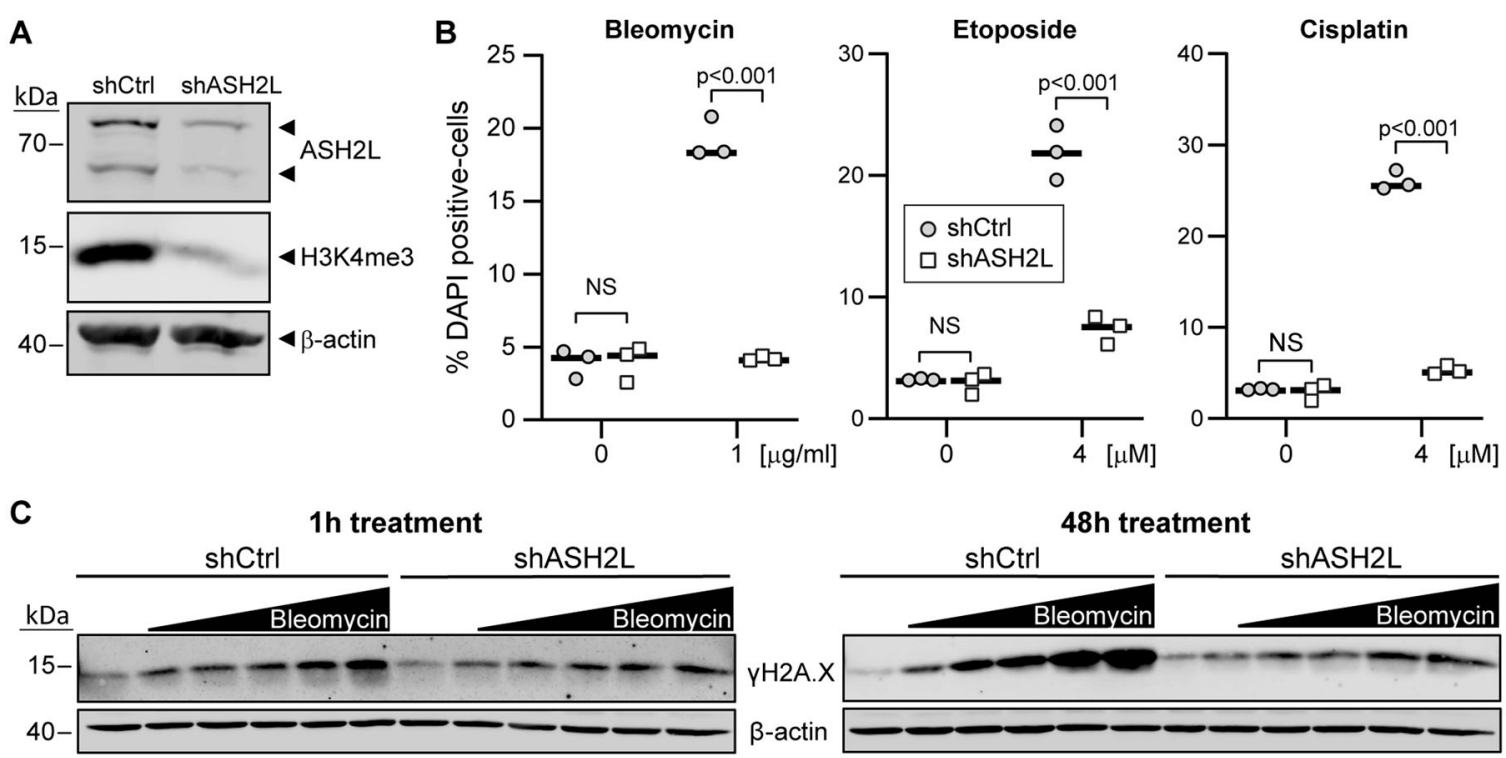

D

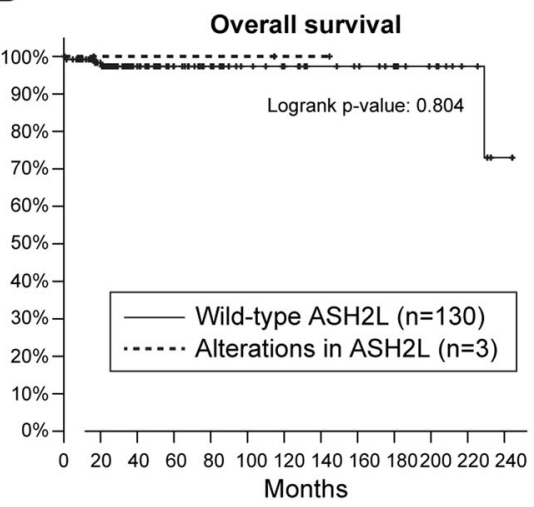

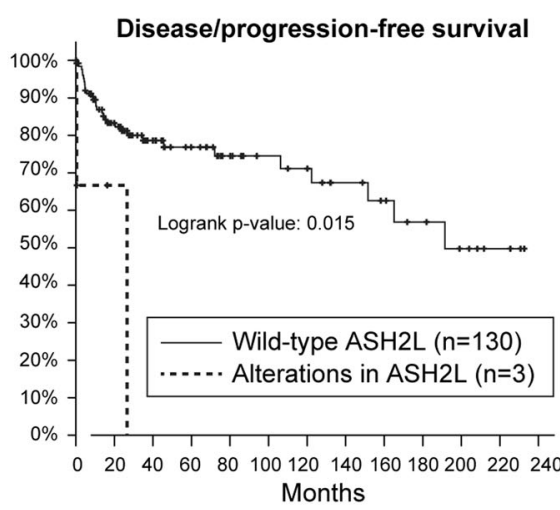

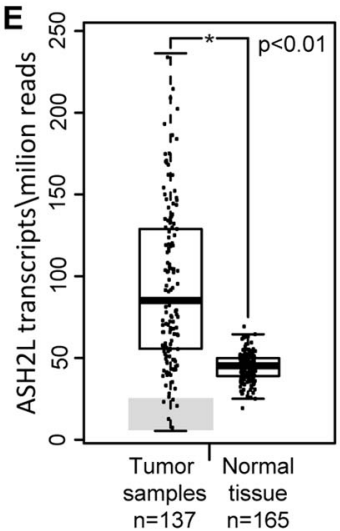

Fig. 5 ASH2L depletion in the NT2D1 testicular cancer cell line leads to resistance to standard therapy. A Western blot depicting shRNAmediated ASH2L knockdown efficiency in NT2D1 TC cells. B Control and ASH2L-silenced NT2D1 cells were treated with the indicated drugs for 72 h. The percentage of dead cells of three independent experiments was quantitated by flow cytometry following DAPI staining. The horizontal bars correspond to the medians. C Control and ASH2L-silenced NT2D1 cells were treated with $0,0.12,0.25,0.5,1$, or $2 \mu \mathrm{g} / \mathrm{ml}$ of bleomycin. One set of cells was harvested at $1 \mathrm{~h}$ and the second set at $48 \mathrm{~h}$ post treatment. The cells were lysed and protein lysates analyzed by western blotting using the indicated antibodies. D Testicular cancer patient survival (left) and relapse (right) graphs from the Tumor Cancer Genome Atlas (TCGA) database for patients with (red line) or without (blue line) alterations in the ASH2L gene. Data obtained through the cBioportal website. Cohort name: Testicular Germ Cell Tumors (TCGA, PanCancer Atlas). E Graph comparing ASH2L transcript levels between testicular cancer samples and normal testicular tissue. The graph was generated through the GEPIA software. This tool requires a minimum fold change to be added to the analysis; here we used 1.74 (or $\log _{2} \mathrm{FC}=0.8$ ), which corresponds to situations where ASH2L expression is significantly upregulated in cancer vs tumor samples and the fold change is at least 1.74. Dataset name: Testicular Germ Cell Tumors (TGCT). The zone shaded in gray corresponds to tumor cases where ASH2L levels are much lower than what is found in control tissues.

accordance with this, we show that ASH2L, a core component of the complex responsible for adding this chromatin mark, is excluded from areas of damaged DNA. Although decreased levels of H3K4me3 have previously been observed in areas of laser damaged $\mathrm{DNA}^{33}$, it was not clear if this is only due to the recruitment of KDM5 enzymes or exclusion of the methylation complexes. Our data indicates that both scenarios occur simultaneously. In accordance with this model, Liu et al. ${ }^{62}$ have used colorectal cancer tissue samples to show a correlation between WDR82 protein levels, H3K4me3, and clinical outcome. WDR82 is a noncore member of the ASH2Lcontaining H3K4 trimethylation complex. Interestingly, patients with low H3K4me3 levels showed less aggressive tumors indicating low proliferation, but had a decreased overall survival compared with the high-expression group. One of the main avenues of treatment for colorectal cancer is radiation therapy, which induces doublestranded DNA damage. These observations are in line with our data obtained in HL and TC cells. 
There is evidence, however, that points toward the exact opposite role of H3K4me3 in cancer progression. Decreased levels of H3K4 trimethylation levels have been suggested to be beneficial in terms of therapeutic outcome, for example in the case of pediatric ependymomas $^{63}$. Further investigations will elucidate whether these discrepancies are due to differences between cancers derived from different tissues, the type of treatment used for these malignancies, or other factors.

It was surprising that no other core members of the complex responsible for $\mathrm{H} 3 \mathrm{~K} 4$ trimethylation were detected alongside ASH2L in our screen. Knockdown of proteins such as WDR5 and DPY30 strongly decreases the levels of H3K4me $3^{64,65}$. Hence, one could have expected that depletion of these genes induces a phenotype similar to what is observed upon ASH2L knockdown. However, a previous study investigating the expression of MLL complex components has shown that the four core components are expressed at higher levels than the methyltransferase subunits ${ }^{66}$. Possibly, these core components have additional functions, independent of H3K4 methylation. In the case of WDR5, transcriptionindependent functions have been reported ${ }^{67,68}$. The observation that, besides ASH2L, none of the other core components are detected in our screen, raises the possibility that ASH2L modulates the response to genotoxins independently of H3K4me3.

Somewhat surprisingly, both WDR5 and DPY30 depletion display an opposite phenotype compared to the one observed upon ASH2L knockdown. Downregulation of WDR5 in colorectal cancer induces DNA damage and chemosensitivity $^{69}$, and knockdown of DPY30 increases the levels of endogenous DNA damage and decreases the DNA repair ability of hematopoietic stem cells ${ }^{70}$. WDR5 and DPY30 are required for the addition of H3K4me3. One possible explanation for the different outcomes observed upon WDR5, DPY30, and ASH2L invalidation could be that ASH2L is the only core member of the methyl-transferase complexes that is required for the addition of the third methyl group. Unlike other core members of these complexes, knockdown of ASH2L does not affect the levels of $\mathrm{H} 3 \mathrm{~K} 4 \mathrm{me} 1$ or $\mathrm{H} 3 \mathrm{~K} 4 \mathrm{me}^{71,72}$. In contrast, knockout of murine ASH2L or DPY30 also induces a decrease in the levels of H3K4me 2 and $\mathrm{me}^{27,28}$.

Our transcriptomic studies comparing control and ASH2L knockdown cells have shown only mild changes in overall gene expression. These changes were not associated with biological processes involving cell death, resistance to DNA damaging drugs, DNA repair, or other biological pathways that could explain the resistance to bleomycin. As H3K4me3 is present at the vast majority of active promoters, decreasing its levels could have subtle effects on transcription. These changes may not individually be detected in our screen but the sum of numerous subtle changes in gene expression brought by ASH2L knockdown may turn out eventually to contribute to genotoxin resistance.

We currently lack the tools to fully distinguish the roles of each individual methyl group on histone 3 lysine 4 . Howe et al. ${ }^{71}$ argue that H3K4me3 is not required for, but more a consequence of, efficient transcription, and that its actual function remains enigmatic. In embryonic stem cells, deletion of Cfp1, a component of Set1 complexes, leads to a drastic decrease in the levels of H3K4me3. Similar to our data, this has only a minimal effect on overall transcription ${ }^{73}$. Moreover, treating embryonic stem cells with doxorubicin, a DNA damaging drug, leads to increased levels of H3K4me3 at hundreds of genes. However, blocking H3K4me3 formation by removing Cfp1 has almost no effect on gene expression, regardless of doxorubicin addition ${ }^{74}$. Therefore, H3K4me3 seems to be expendable for gene transcription and responsiveness.

Although we could not fully disentangle the relationship between ASH2L, H3K4me3, and resistance to DNA damaging agents, the results presented here clearly indicate that low levels of ASH2L in cancer cells could be used to predict genotoxin resistance but not resistance to ATR inhibitors, which are in clinical trials at the moment ${ }^{75}$.

\section{Conclusion}

ASH2L was initially regarded as an oncogene ${ }^{31}$. Our study indicates that it can also act as a tumor suppressor as its knockdown increases the resistance of tumor cell lines treated with various genotoxins (bleomycin, etoposide, and cisplatin). However, ASH2L knockdown does not confer resistance to ATR or ATM inhibitors. Patients with low levels of ASH2L or H3K4me3 may be more likely to relapse when treated with DNA damaging chemotherapy but they should remain responsive to other anticancer drugs such as ATM or ATR inhibitors. ASH2L or H3K4me3 levels could prove useful as biomarkers in the clinic.

\section{Methods \\ Cell lines}

L1236 HL cells were purchased from DSMZ (ref: ACC 530 ) and grown in RPMI media. NT2D1 cells were purchased from ATCC (ref: CRL-1973) and grown in DMEM media. U2OS cells were purchased from ATCC (ref: HTB96). U2OS cells with stably integrated HR (DR-GFP) and nonhomologous end joining (EJ5GFP) reporters were a kind gift from the laboratory of Jeremy Stark (City of Hope Comprehensive Cancer Center, CA 91010). U2OS cells were grown in DMEM media. All cell culture media was supplemented with $10 \%$ fetal bovine serum and the cell lines were grown in $5 \% \mathrm{CO}_{2}$ and a humidified atmosphere. 


\section{CRISPR/Cas9 whole-genome unbiased gene knockout screen}

L1236 cells stably expressing the Cas9 protein were generated by transducing L1236 cells with viral particles created with LentiCas9-Blast (see details below). The cells were selected with $5 \mu \mathrm{g} / \mathrm{ml}$ blasticidin for 7 days. The GeCKO v2 library was purchased from Addgene (twoplasmid system catalog number 1000000049), and amplified in bacteria as previously described ${ }^{76}$ and following the recommendations of the library creators ${ }^{77}$. The library was packaged into viral particles (see lentivirus production section below). Then, we used $205 \times 10^{6}$ L1236 cells stably expressing the Cas9 protein for transduction with the GeCKO viral library. Cells were plated at a density of $3 \times 10^{6}$ cells per well of 12 -well plates (in $3 \mathrm{ml}$ media) and immediately infected with concentrated virus at a multiplicity of infection of 0.4 to insure that most cells only expressed one sgRNA. Sixteen hours later, cells were trypsinized, seeded in T150 flasks $(200,000$ cells $/ \mathrm{ml} ; 40 \mathrm{ml}$ per flask) and cultured in the presence of $1 \mu \mathrm{g} / \mathrm{ml}$ puromycin to get rid of the non-infected cells. Seven days later, $7 \times 10^{7}$ cells were harvested ("Time 0 " sample), $7 \times$ $10^{7}$ cells were left to grow untreated for 10 days (and passaged as necessary), and $7 \times 10^{7}$ cells were grown for 10 days in the presence of $250 \mathrm{ng} / \mathrm{ml}$ bleomycin. The bleomycin-containing medium was changed every other day. The genomic DNA of the cells was extracted (see section below) and used undiluted for polymerase chain reaction (PCR) amplification using primers binding $5^{\prime}$ or $3^{\prime}$ of the sgRNA sequence integrated in the cell's genomes $^{78}$. In a $50 \mu$ reaction, $7 \mu \mathrm{g}$ DNA was used as template, $0.25 \mu \mathrm{M}$ final primer concentration, and $25 \mu \mathrm{l}$ of NEBNext High Fidelity PCR Master $2 \times$ Mix (New Englarnd Biolabs, M0541L). The primer sequences and their description, along with the PCR program, are available in Table S4. PCR amplicons were gel extracted (260 base pair band) and sent for next generation sequencing at the University of Lausanne, Genomic Technologies Facility (https://wp.unil.ch/gtf). Differential sgRNA distribution analysis between the control and ASH2L silenced cells was performed using the MAGeCK algorithm ${ }^{25}$.

\section{Genomic DNA extraction}

Cells were washed once in cold phosphate-buffered saline (PBS) and resuspended in lysis buffer (1\% sodium dodecyl sulphate (SDS), $50 \mathrm{mM}$ EDTA, $50 \mathrm{mM}$ Tris, $\mathrm{pH}$ 8 ). For $3.5 \times 10^{7}$ cells, we used $6 \mathrm{ml}$ lysis buffer. Next, we added $30 \mu \mathrm{l}$ of $20 \mathrm{mg} / \mathrm{ml}$ proteinase K (Roche 03115828 001). The samples were incubated overnight at $55^{\circ} \mathrm{C}$. Afterwards, $15 \mu \mathrm{l}$ of $20 \mathrm{mg} / \mathrm{ml}$ RNase A (Roche 10109169001) was added to the samples that were then quickly vortexed and incubated at $37{ }^{\circ} \mathrm{C}$ for $30 \mathrm{~min}$, followed by a $10 \mathrm{~min}$ incubation on ice. At this point, $2 \mathrm{ml}$ of cold 7.5 $\mathrm{M}$ ammonium acetate was added to the samples that were then vortexed for $15 \mathrm{~s}$ and centrifuged at $4000 \times g$ for $10 \mathrm{~min}$. The supernatant was transferred to a new tube on which $6 \mathrm{ml}$ of isopropanol (100\%) was added. The tubes containing the samples were inverted 15-25 times and then centrifuged at $4000 \times g$ for $10 \mathrm{~min}$. The supernatant was gently discarded and the remaining pellet was washed once with $70 \%$ ethanol. The ethanol was removed after an additional $4000 \times g$ centrifugation for $2 \mathrm{~min}$ and the pellet was air dried for $5 \mathrm{~min}$. The DNA pellet was resuspended in $0.5 \mathrm{ml}$ TE buffer (Sigma T9285) and incubated at $65^{\circ} \mathrm{C}$ for $1 \mathrm{~h}$. The tubes were left to cool at room temperature and then the DNA concentration was measured via Nano-Drop apparatus (Thermo Fisher).

\section{Western Blotting}

Cells were harvested by trypsinization (attached cell lines) or centrifugation (L1236 cells) and washed once with cold PBS. The cell pellets were resuspended in cold radioimmunoprecipitation assay buffer $(20 \mathrm{mM}$ Tris-Cl $\mathrm{pH}$ 8.0, $1 \mathrm{mM}$ EDTA, 1\% Triton X-100, 1\% sodium deoxycholate, $0.1 \%$ SDS, $150 \mathrm{mM} \mathrm{NaCl}$ ) supplemented with cOmplete protease inhibitor (Roche 11836145001) and PhosStop (Roche 04906837001), for $30 \mathrm{~min}$ on ice with occasional mixing. The samples were sonicated for $5 \mathrm{~s}$ at $40 \%$ amplitude using a Vibra-Cell 75186 machine. The tubes were centrifuged at $14,000 g, 4{ }^{\circ} \mathrm{C}$ for $10 \mathrm{~min}$ and the supernatant was used for protein quantification using the BCA method (Pierce 23225). Samples were mixed with $2 \times$ Laemmli buffer and incubated for $10 \mathrm{~min}$ at $95{ }^{\circ} \mathrm{C}$. Thirty microgram of protein was loaded per lane on either $15 \%, 10 \%$, or $4-20 \%$ polyacrylamide gels. The nitrocellulose membranes were blocked for $30 \mathrm{~min}$ at RT with $5 \%$ bovine serum albumin (BSA) dissolved in TBST solution. Antibodies were diluted (1:2000) in TBST with $5 \%$ BSA, and incubated overnight at $4{ }^{\circ} \mathrm{C}$ with gentle shaking. Membranes were washed three times with TBST and incubated with fluorochrome conjugated secondary antibodies (Invitrogen, A21109, A21057, or A32735), for $1 \mathrm{~h}$ at room temperature. Membranes were then washed 3 times with TBST and scanned using a Lycor Odyssey system. For signal quantification, a rectangular region was drawn around a band of interest in the Lycor Odyssey software, background was established by drawing an identical region, in a portion of the blot with no visible bands. The background signal was subtracted from the band signal, and the values were used to make the graphs.

\section{Presto-Blue cell number assay}

We used the Presto-Blue viability (Thermo A13262) reagent according to the manufacturer's instructions. Briefly, L1236 cells were plated at $2 \times 10^{3}$ cells per well of 96-well plates containing $100 \mu \mathrm{l}$ of media per well. The cells were then treated with the indicated doses of drugs for $72 \mathrm{~h}$. Presto-Blue reagent was added to each well 
$\left(10 \mu \mathrm{l} /\right.$ well) and the plates were incubated for $2 \mathrm{~h}$ at $37^{\circ} \mathrm{C}$ and $5 \% \mathrm{CO}_{2}$. The fluorescence was read at $560 / 590 \mathrm{~nm}$ (excitation/emission) using a Cytation-3 plate reader. The value of the blank samples (media with no cells but with Presto-Blue) was deducted from all wells and the remaining absorbance values were plotted in the graphs. For the proliferation assay shown in Fig. 1f, control and ASH2L depleted L1236 cells were plated in 96-well plates at 1000 cells per well. Presto-Blue assay was performed each day, from day 0 to day 6.

\section{DAPI viability assay}

Cells were plated in 12 -well plates $\left(4 \times 10^{4}\right.$ for NT2D1 cells, and $1 \times 10^{5}$ for L1236 cells) and treated with genotoxins for the indicated amounts of time. Floating and attached cells were harvested and incubated directly (without washing) with DAPI (Thermo 62248) at a final concentration of $1 \mu \mathrm{g} / \mathrm{ml}$ in the media they were grown in. After 10 min the cells were analyzed on a CytoFlexS flow cytometer, on the KO525 channel. A gate was placed on the single cells, and subsequently on the DAPIpositive cells.

\section{5-bromo-2'-deoxyuridine (BrdU) incorporation assay and propidium iodide cell cycle}

L1236 cells were infected with control and ASH2Lspecific shRNA-encoding viruses and grown in the presence of doxycycline for 4 days in order for the knockdown to occur (see the "shRNA-mediated knockdown of ASH2L" section below). Thirty minutes before harvesting, BrdU (10 $\mu \mathrm{M}$ final concentration) was added to the cell cultures. Unless otherwise stated, the next steps were performed at $4{ }^{\circ} \mathrm{C}$. Two million cells were harvested and washed with $1.5 \mathrm{ml}$ PBS, and then resuspended in $300 \mu \mathrm{l}$ PBS. Next, $700 \mu \mathrm{l} 100 \%$ ethanol was added to the tubes under gentle vortexing to prevent clumping. The cells were then kept overnight at $4{ }^{\circ} \mathrm{C}$. The next day, the cells were washed once with $1.5 \mathrm{ml}$ of PBS and then incubated in $500 \mu \mathrm{l} 0.1 \mathrm{M} \mathrm{HCl}, 0.5 \%$ Triton X-100 in PBS for $10 \mathrm{~min}$. The tubes were centrifuged at $170 \times g$ for $5 \mathrm{~min}$ (we recommend a swing-out centrifuge for these samples, as the cells can stick to the sides of the tubes in regular angled centrifuges). The pellets were resuspended in $500 \mu \mathrm{l}$ water, boiled for $10 \mathrm{~min}$, and cooled down on ice for $10 \mathrm{~min}$. Then, $1 \mathrm{ml}$ of $0.5 \%$ Triton X-100 in PBS was added and the tubes were centrifuged as above. The pellets were resuspended in $50 \mu \mathrm{l}$ PBS containing 1\% BSA and $0.5 \%$ Tween and $1 \mu \mathrm{l}$ of primary FITC-labeled antiBrdU antibody added to each sample. The tubes were placed in the dark for one hour. Then, $1.45 \mathrm{ml}$ of PBS was added and the cells were centrifuged $(170 \times \mathrm{g}$ for 5 minutes), the pellets were resuspended in $500 \mu \mathrm{l}$ PBS containing $40 \mu \mathrm{g} / \mathrm{ml}$ propidium iodide and $200 \mu \mathrm{g} / \mathrm{ml}$ RNase A. The tubes were incubated at $37^{\circ} \mathrm{C}$ for $30 \mathrm{~min}$, and then analyzed by flow cytometry using the FITC and PE channels, of a FC-500 flow cytometer (Beckman Coulter). All manipulations were performed in $1.7 \mathrm{ml}$ Eppendorf tubes. The data were analyzed as follows: a gate was placed on single cells, and a second gate (dependent of the first one) was placed on FITC-positive (BrdU positive) cells. The geometric mean of all events in the BrdU-positive gate was used to generate the graph in Fig. 1g. For figure S1D, a gate was placed on single events, and the rest of the gates are shown in the representative example.

\section{DNA repair reporter assays}

The U2OS cells with stably integrated HR (DR-GFP) and nonhomologous end joining (EJ5-GFP) reporters were a kind gift from Jeremy Stark (City of Hope, Beckman Research Institute of the City of Hope, CA, 91010, USA). These cells were plated in 6 -well plates $\left(8 \times 10^{4}\right.$ cells/well) and immediately transfected with a pool of control siRNAs or a pool of siRNAs targeting ASH2L (see siRNA transfection protocol below). The next day, siRNA transfection was repeated. On the following day, the cells were transduced with a virus (multiplicity of infection of 1) carrying an I-SceI endonuclease gene. The next day, media was changed and the cells were left to grow for another $48 \mathrm{~h}$ period. The cells were then trypsinized and washed once with PBS. One-quarter of the cells was used for western blot analysis to check knockdown efficiency. The rest of the cells was analyzed on a CytoFlexS flow cytometer, gating on GFP-positive single cells.

\section{RNA isolation and sequencing and analysis}

L1236 harboring inducible shRNAs were plated at a $2 \times$ $10^{6}$ cells per $10-\mathrm{cm}$ plate density and stimulated 4 days with $1 \mu \mathrm{g} / \mathrm{ml}$ doxycycline. The cells were washed twice in cold PBS and total RNA was extracted using a High Pure RNA isolation kit (Roche 11828665001). Reverse transcribed RNA was used for sequencing by the University of Lausanne, Genomic Technologies Facility. Fastq files were demultiplexed and adapters were trimmed using Cutadapt $^{79}$. Fastq screen was used to remove ribosomal RNA sequences. $\mathrm{STAR}^{80}$ was used to align the reads against the Homo sapiens GRCh38.92 genome. Differential gene expression was computed with limma ${ }^{81}$ by fitting the six samples into a linear model and performing the comparison between shASH2L and shControl. As the experiment was performed in batches and samples are paired, pairing was corrected for in the linear model. Moderated $t$ test was used for the comparison between shCtrl and shASH2L samples. In order to correct for multiple testing, we used the Benjamini-Hochberg method $^{82}$ to calculate the FDR (also known as adjusted $p$ value). Heatmaps were generated from $\log _{2}$ expression values, using the expression module of the heatmapper.ca 
online application. The $Z$ score in the heat-maps is calculated by subtracting the mean of the row from each value and then dividing the resulting values by the $\mathrm{SD}$ of the row. The GO analysis was performed using the online Protein ANalysis THrough Evolutionary Relationships (PANTHER) classification system developed by Huaiyu et al. ${ }^{83}$.

\section{Laser microirradiation}

Wild-type U2OS cells were plated on glass bottom $35 \mathrm{~mm}$ culture dishes (MaTek P35G-1.5-14-C) at a density of $5 \times 10^{5}$ cells per dish and incubated overnight. Ten minutes before transporting the cells to the confocal microscope, Live-Hoechst (Invitrogen H3570) was added to the cells at a final concentration of $1 \mu \mathrm{g} / \mathrm{ml}$. This allows for the visualization of nuclei and also acts as a sensitizing agent. The live cells were microirradiated using the $405 \mathrm{~nm}$ X-Cite light source and the fluorescence recovery after photobleaching (FRAP) module of a Zeiss LSM 710 confocal microscope. Stripes within cells were irradiated using $100 \%$ of the laser power (5 iterations, pixel dwell time $50.1 \mu \mathrm{s})$. Fifteen minutes post irradiation, the cells were washed once with PBS and then incubated with CSK $+\mathrm{R}$ buffer (10 mM Pipes, pH 7.0, $100 \mathrm{mM} \mathrm{NaCl}, 300 \mathrm{mM}$ sucrose, and $3 \mathrm{mM} \mathrm{MgCl}_{2}, 0.5 \%$ Triton X-100, and $0.3 \mathrm{mg} / \mathrm{ml}$ RNAse A) two times for $3 \mathrm{~min}$ at room temperature to remove soluble proteins. The cells were then washed once with $2 \mathrm{ml}$ PBS and fixed with $4 \%$ paraformaldehyde for $15 \mathrm{~min}$. This was followed by two PBS washes and the addition of $2 \mathrm{ml}$ of PBS containing 5\% fetal bovine serum and $0.3 \%$ Triton X-100. The samples were co-incubated with anti-ASH2L and anti phosphoH2A.X antibodies diluted (according to their datasheet) in PBS containing $1 \%$ BSA and $0.3 \%$ Triton X-100, overnight at $4{ }^{\circ} \mathrm{C}$. The next day, the plates were washed twice with $2 \mathrm{ml}$ PBS and the secondary antibodies were added, diluted in the same buffer. One hour later, the plates were washed, and PBS containing $1 \mu \mathrm{g} / \mathrm{ml}$ Live-Hoechst was added for $10 \mathrm{~min}$ at room temperature. The cells were washed three times with PBS and glass coverslips were mounted using VectaShield (Vector laboratories H-1000$10)$, and sealed with nail polish. The next day, the dishes were imaged using the same confocal microscope that was used for the irradiation.

\section{Lentivirus production}

Low passage HEK 293T cells were plated $\left(1 \times 10^{6}\right.$ cells/ plate; in $10 \mathrm{ml}$ media) in $10 \mathrm{~cm}$ dishes, and left to adhere overnight. The cells were transfected using the calcium phosphate method ${ }^{84}$, with $7.5 \mu \mathrm{g}$ psPAX2, $2.5 \mu \mathrm{g}$ pMD2. G, and $10 \mu \mathrm{g}$ of specific cDNA or shRNA lentiviralencoding plasmids. Briefly, chloroquine (Sigma C6628) was added to the media to a final concentration of $25 \mu \mathrm{M}$. In a sterile tube, the DNA and sterile water were mixed to a final volume of $450 \mu$ l. After the addition of $50 \mu \mathrm{l}$ of $2.5 \mathrm{M} \mathrm{CaCl}_{2}$ solution, the samples were mixed and incubated $20 \mathrm{~min}$ at room temperature. Then, $500 \mu \mathrm{l}$ of a $2 \times$ HEPES solution $\left(\mathrm{NaCl} 280 \mathrm{mM}, \mathrm{KCl} 10 \mathrm{mM}, \mathrm{Na}_{2} \mathrm{HPO}_{4}\right.$ $1.5 \mathrm{mM}$, D-glucose $12 \mathrm{mM}$, HEPES $50 \mathrm{mM}$ ) were added and the tube contents were briefly mixed. One minute after the HEPES buffer was added, the contents of the tube were added dropwise to the cells. Eight hours later, the media was changed and the cells were grown for 48 more hours. Next, the media was collected and centrifuged at $2500 \mathrm{rpm}$ for $5 \mathrm{~min}$ to remove floating cells. The resulting supernatant containing the viral particles was aliquoted and stored at $-80^{\circ} \mathrm{C}$. Titration was performed using puromycin selection of infected cells. Unless specified otherwise, the minimal volume of viruses conferring $100 \%$ protection against puromycin was used in subsequent experiments.

\section{siRNA transfection}

U2OS cells were plated in $1 \mathrm{ml}$ of DMEM at $4 \times 10^{4}$ per well in 6-well plates. The first round of siRNA transfection was performed right after the plating when the cells were still floating. The transfection mix was made as follows: $200 \mu \mathrm{l}$ Opti-MEM (Thermo 11058021) were added to a sterile $1.7 \mathrm{ml}$ Eppendorf tube, then $1.2 \mu \mathrm{l}$ of siRNA $(5 \mu \mathrm{M}$ stock) was added, followed by $2 \mu \mathrm{l}$ of Lipofectamine RNAi-MAX (Invitrogen 13778-075). The tube was gently mixed and incubated at room temperature for $15 \mathrm{~min}$. This mixture was added dropwise in the well containing the cells. The next day the media was replaced with $1 \mathrm{ml}$ of fresh media and the transfection was repeated one more time. The cells were analyzed $96 \mathrm{~h}$ after the first transfection. The final siRNA concentration in the media was $5 \mathrm{nM}$. The pools of 30 siRNAs targeting ASH2L (ref\# 9070), and the siRNA negative control (ref\# si-C005-NEG001, a pool of 30 nontargeting siRNA sequences), were purchased from the siTOOLS Biotech company.

\section{shRNA-mediated knockdown of ASH2L}

L1236 and NT2D1 cells were transduced with doxycycline-inducible shRNA carrying lentiviruses at an MOI of 0.5 (this was achieved with about $0.25 \mathrm{ml}$ of nonconcentrated viral supernatant added to $2 \mathrm{ml}$ of media containing $10^{6}$ cells). We checked via western blotting that there was no ASH2L knockdown in the absence of doxycycline. For knockdown experiments, $2 \times 10^{6}$ cells were plated in $10 \mathrm{~cm}^{2}$ plates, and cultured in the presence of $1 \mu \mathrm{g} / \mathrm{ml}$ of doxycycline for 4 days. Afterwards, the cells were recounted and plated for experiments in 6,12 , or 96-well plates, depending on the type of experiment performed. The shRNA sequence targeting ASH2L was 5'-T TTACCAAGAATACATCTC- $3^{\prime}$ and the control shRNA sequence was: 5'-CACACAACATGTAAACCAGGGA-3'. 


\section{cDNA transfection}

NT2D1 cells were plated in 12 -well plates, at $1 \times 10^{5}$ cells per well, in $700 \mu \mathrm{l}$ media, and left to adhere overnight. The next day the media was changed for $700 \mu \mathrm{l}$ fresh media. In a sterile tube, $1 \mu \mathrm{g}$ DNA was mixed with $100 \mu \mathrm{l}$ Opti-MEM media, and $1 \mu \mathrm{l}$ Lipofectamine 2000 (Invitrogen 11668-019) was added. The tube was gently mixed and incubated at room temperature for $30 \mathrm{~min}$. The mixture was added dropwise in the wells. The media was changed the next day, and cells were analyzed $48 \mathrm{~h}$ post transfection.

\section{Antibodies}

The antibody against ASH2L used for Western blots was from Bethyl (A300-489; lot 2) and the one used for immunocytochemistry was from Cell Signaling (CLS D93F6; lot 1). The antibodies against H3K4me3 (Ab8580; lot GR3264593-1), H3K9me3 (Ab176916; Lot GR2318257-2), H3K27me3 (Ab192185; lot GR3264827), and phospho-ATM at serine 1981 (Ab81292; lot GR217573-6) were purchased from Abcam. The antibody against phospho-H2A.X at serine 139 was acquired from Milipore (5636; lot 2554898), and the one against beta actin from Cell signaling (CLS4970; lot 14). Our anti FLAG antibody was purchased from Sigma (F1804-1MG; lot SLGB5673V). The FITC-labeled anti-BrdU antibody was purchased from Thermo Fisher Scientific (11-507142 , lot 4315462)

\section{Chemicals}

The following chemicals were purchased from SigmaAldrich: ATM inhibitor KU-60019 (SML1416-5MG), ATR inhibitor AZ-20 (SML1328-5MG), bleomycin (B8416), etoposide (E1383), doxycycline (D3072), cisplatin (P4394), 5-Bromo-2'-deoxyuridine (B5002). Puromycin was purchased from Thermo-Fisher (A1113802), blasticidin S was purchased from Carl Roth (CP14.2).

\section{Statistical analysis}

For the dose-response curves, the area under the curve (AUC) was calculated for each group (shCtrl and shASH2L) on a linear scale. The resulting AUC values and the standard errors were used to perform an unpaired $t$ test between the two groups. The " $n$ " for the $t$ test was not 3 . The " $n$ " was equal to the degrees of freedom $(\mathrm{d} f)$ of each curve. The $\mathrm{d} f$ was calculated as follows: number of data points used for one curve (27) minus the number of concentrations $(9)+1$ (because the $t$ test subtracts 1 automatically). All calculations were performed in GraphPad 8 software (La Jola, California, USA) according to AUC statistics module and validated by the University of Lausanne Biostatistics platform (https://wp.unil.ch/ biostatistics/). The same analysis was done for the growth curve in Fig. 1f, and the WB quantification in Fig. 2e. For Fig. 1e and S2D, we performed unpaired $t$ tests, and the $p$ values were corrected for multiple testing with the Benjamini and Hochberg method. For Figs. 1g, 2c, 5b, S2E, and S5 we performed two-tailed unpaired student's $t$ tests. At least three independent experiments were performed. Data are shown as median together with the individual measurements.

\section{Plasmids}

LentiCas9-Blast (\#849) is a third generation lentiviral vector expressing the human codon-optimized $S$. pyogenes Cas 9 protein (tagged at the C-terminus with FLAG) and blasticidin (both genes driven by the EFS-NS promoter). This plasmid was a gift from Feng Zhang (Addgene plasmid \# 52962; http://n2t.net/addgene:52962; RRID: Addgene_52962) ${ }^{85}$.

The pcDNA3 plasmid (\#1) is a mammalian, CMV-driven, expression vector.

The hASH2L.dn3 (\#1055) pcDNA3-based plasmid encodes the human ASH2L $80 \mathrm{kDa}$ isoform (NM_001105214.2), the most commonly expressed isoform in cells and tissues. This plasmid was a gift from Kai Ge (Addgene plasmid \#15548; http://n2t.net/addgene:15548; RRID:Addgene_15548) ${ }^{86}$.

The pLentiPURO-tetO-V5-6xHis (\#980) is a lentiviral backbone for mammalian expression of cDNAs. This plasmid was a gift from Ie-Ming Shih (Addgene plasmid \# 39481; http://n2t.net/addgene:39481; RRID:Addgene_39481) ${ }^{87}$.

The hASH2L.plp (\#1052) is a hASH2L-encoding lentiviral vector. The plasmid was made by cutting out the hASH2L insert from hASH2L.dn3 (mentioned above, \#1055) using BamHI and XhoI and ligating it into the receiving lentiviral vector (pLentiPuro) opened with the same enzymes.

The HA-Flag-hKDM5A (with intron 27).dn3 (\#1048) was a gift from William Kaelin (Addgene plasmid \# 14799; http://n2t.net/addgene:14799; RRID:Addgene_14799) ${ }^{88}$. It expresses an N-terminally HA- and FLAG-tagged human lysine demethylase KDM5A in the pcDNA3 backbone. Sequencing this plasmid revealed the presence of 82 base pairs of intron 27 before the last exon of the codon sequence. This plasmids encodes a functional protein (https://www.ncbi.nlm.nih.gov/pubmed/17320163).

HA-NLS-scSceI-IRES-BFP.pCVL (\#1053) plasmid expresses the HA-tagged I-SceI-encoding sequence followed by an IRES and the coding sequence for the Blue Fluorescent Protein. There is a nuclear localization sequence inserted between the HA tag and I-SceI. This construct was a gift from Andrew Scharenberg (Addgene plasmid \#45574 http://n2t.net/addgene:45574; RRID: Addgene_45574) $)^{89}$.

The shCtrl.lti (\#1056) and shASH2L.lti (\#1057) were purchased from Horizon Discovery (VSC11655 and V3SH11252-225078488, respectively). They code for shRNA sequences (described above under the "shRNA-mediated 
knockdown of ASH2L" section) and Turbo-RFP that are both under a doxycycline-inducible promoter.

The packaging vector psPAX2 (\#842) and the envelope vector pMD2.G (\#554) were gifts from Didier Trono (Addgene plasmids \#12260 and \#12259, respectively) ${ }^{90}$.

\section{Acknowledgements}

We thank Mr. Gilles Dubuis for his expert technical assistance. We also thank, at the University of Lausanne, the Cellular Imaging Facility for its support in image acquisition, the Genomic Technologies Facility for its support in sequence generation and analyses, and the Biostatistics platform for its counseling and statistical method validation.

\section{Conflict of interest}

The authors declare that they have no conflict of interest.

\section{Publisher's note}

Springer Nature remains neutral with regard to jurisdictional claims in published maps and institutional affiliations.

Supplementary Information accompanies this paper at (https://doi.org/ 10.1038/s41419-020-03231-0).

Received: 20 August 2020 Revised: 12 November 2020 Accepted: 12 November 2020

Published online: 30 November 2020

\section{References}

1. Bray, F. et al. Global cancer statistics 2018: GLOBOCAN estimates of incidence and mortality worldwide for 36 cancers in 185 countries. CA Cancer J. Clin. $\mathbf{6 8}$, 394-424 (2018)

2. Dagenais, G. R. et al. Variations in common diseases, hospital admissions, and deaths in middle-aged adults in 21 countries from five continents (PURE): a prospective cohort study. The Lancet https://doi.org/10.1016/S0140-6736(19) 32007-0.

3. Torgovnick, A. \& Schumacher, B. DNA repair mechanisms in cancer development and therapy. Front. Genet. 6, 157 (2015).

4. Cheung-Ong, K., Giaever, G. \& Nislow, C. DNA-damaging agents in cancer che motherapy: serendipity and chemical biology. Cell Chem. Biol. 20, 648-659 (2013).

5. Flores-Pérez, A. et al. RAD50 targeting impairs DNA damage response and sensitizes human breast cancer cells to cisplatin therapy. Cancer Biol. Ther. 15 777-788 (2014).

6. Harper, J. W. \& Elledge, S. J. The DNA damage response: ten years after. Mol. Cell 28, 739-745 (2007).

7. Reinhardt, H. C., Cannell, I. G., Morandell, S. \& Yaffe, M. B. Is post-transcriptional stabilization, splicing and translation of selective mRNAs a key to the DNA damage response? Cell Cycle 10, 23-27 (2011)

8. Surova, O. \& Zhivotovsky, B. Various modes of cell death induced by DNA damage. Oncogene 32, 3789-3797 (2013)

9. Dietlein, F., Thelen, L. \& Reinhardt, H. C. Cancer-specific defects in DNA repair pathways as targets for personalized therapeutic approaches. Trends Genet. 30, 326-339 (2014).

10. Della Latta, V., Cecchettini, A., Del Ry, S. \& Morales, M. A. Bleomycin in the setting of lung fibrosis induction: from biological mechanisms to counteractions. Pharm. Res. 97, 122-130 (2015).

11. Nicolay, N. H. et al. Mesenchymal stem cells are sensitive to bleomycin treatment. Sci. Rep. 6, 26645 (2016).

12. Chen, J., Ghorai, M. K., Kenney, G. \& Stubbe, J. Mechanistic studies on bleomycin-mediated DNA damage: multiple binding modes can result in double-stranded DNA cleavage. Nucleic Acids Res. 36, 3781-3790 (2008).

13. Roy, B. \& Hecht, S. M. Hairpin DNA sequences bound strongly by bleomycin exhibit enhanced double-strand cleavage. J. Am. Chem. Soc. 136, 4382-4393 (2014).

14. Froudarakis, $M$. et al. Revisiting bleomycin from pathophysiology to safe clinical use. Crit. Rev. Oncol. Hematol. 87, 90-100 (2013).
15. Bartlett, N. L. Fine-tuning the treatment of Hodgkin's lymphoma. N. Engl. J. Med. 374, 2490-2492 (2016).

16. Martin, W. G. et al. Bleomycin pulmonary toxicity has a negative impact on the outcome of patients with Hodgkin's lymphoma. J. Clin. Oncol. 23, 7614-7620 (2005).

17. O'Sullivan, J. M. Predicting the risk of bleomycin lung toxicity in patients with germ-cell tumours. Ann. Oncol. 14, 91-96 (2003).

18. Fox, K. M., Josephson, N. C. \& Richhariya, A. Toxicity burden of bleomycin treatment in hodgkin lymphoma: a systematic literature review. Blood $\mathbf{1 2 8}$ 3566-3566 (2016)

19. Ruthenburg, A. J., Allis, C. D. \& Wysocka, J. Methylation of lysine 4 on histone $\mathrm{H} 3$ : intricacy of writing and reading a single epigenetic mark. Mol. Cell 25 15-30 (2007).

20. Voigt, P., Tee, W.-W. \& Reinberg, D. A double take on bivalent promoters. Genes Dev. 27, 1318-1338 (2013).

21. Kanayama, K et al. Genome-wide mapping of bivalent histone modifications in hepatic stem/progenitor cells. Stem Cells Int. 2019, 9789240-9789240 (2019).

22. Bernstein, B. E. et al. A bivalent chromatin structure marks key developmental genes in embryonic stem. Cells Cell 125, 315-326 (2006).

23. Wang, T., Wei, J. J., Sabatini, D. M. \& Lander, E. S. Genetic screens in human cells using the CRISPR-Cas9 system. Science https://doi.org/10.1126/science.1246981 (2014).

24. Joung, J. et al. Genome-scale CRISPR-Cas9 knockout and transcriptional activation screening. Nat. Protoc. 12, 828-863 (2017).

25. Li, W. et al. MAGeCK enables robust identification of essential genes from genome-scale CRISPR/Cas9 knockout screens. Genome Biol. 15, 554 (2014).

26. Stoller, J. Z. et al. Ash2l interacts with Tbx1 and is required during early embryogenesis. Exp. Biol. Med. 235, 569-576 (2010).

27. Yang, Z., Shah, K., Khodadadi-Jamayran, A. \& Jiang, H. Dpy30 is critical for maintaining the identity and function of adult hematopoietic stem cells. J. Exp. Med. 213, 2349-2364 (2016).

28. Lüscher-Firzlaff, J. et al. Hematopoietic stem and progenitor cell proliferation and differentiation requires the trithorax protein Ash2l. Sci. Rep. 9, 8262 (2019).

29. Wu, Y.-J. et al. ZNF479 downregulates metallothionein-1 expression by regulating ASH2L and DNMT1 in hepatocellular carcinoma. Cell Death Dis. 10, 408 (2019).

30. Zhang, Z., Huang, X., Wang, E., Huang, Y. \& Yang, R. Suppression of Mll1complex by Stat3/Cebpß-Induced miR-21a/21b/181b maintains the accumulation, homeostasis, and immunosuppressive function of polymorphonuclear myeloid-derived suppressor cells. J. Immunol. 204, 3400-3415 (2020).

31. Lüscher-Firzlaff, J. et al. The human trithorax protein hASH2 functions as an oncoprotein. Cancer Res. 68, 749 (2008).

32. Zhang, T., Cooper, S. \& Brockdorff, N. The interplay of histone modificationswriters that read. EMBO Rep. 16, 1467-1481 (2015).

33. Gong, F., Clouaire, T., Aguirrebengoa, M., Legube, G. \& Miller, K. M. Histone demethylase KDM5A regulates the ZMYND8-NuRD chromatin remodeler to promote DNA repair. J. Cell Biol. 216, 1959-1974 (2017).

34. $\mathrm{Xu}, \mathrm{W}$. et al. KDM5B demethylates H3K4 to recruit XRCC1 and promote chemoresistance. Int. J. Biol. Sci. 14, 1122-1132 (2018).

35. Li, X. et al. Histone demethylase KDM5B is a key regulator of genome stability. Proc. Natl Acad. Sci. USA 111, 7096 (2014)

36. Bayo, J. et al. Jumonji inhibitors overcome radioresistance in cancer through changes in H3K4 methylation at double-strand breaks. Cell Rep. 25, 1040-1050. e1045 (2018).

37. Pierce, A. J., Johnson, R. D., Thompson, L. H. \& Jasin, M. XRCC3 promotes homology-directed repair of DNA damage in mammalian cells. Genes Dev. 13 2633-2638 (1999)

38. Bennardo, N., Cheng, A., Huang, N. \& Stark, J. M. Alternative-NHEJ is a mechanistically distinct pathway of mammalian chromosome break repair. PLOS Genet. 4, e1000110-e1000110 (2008)

39. Kuo, L. J. \& Yang, L.-X. Y-H2AX - a novel biomarker for DNA double-strand breaks. Vivo 22, 305-309 (2008).

40. Hyun, K., Jeon, J., Park, K. \& Kim, J. Writing, erasing and reading histone lysine methylations. Exp. Mol. Med. 49, e324-e324 (2017)

41. Mungamuri, S. K., Wang, S., Manfredi, J. J., Gu, W. \& Aaronson, S. A. Ash2L enables P53-dependent apoptosis by favoring stable transcription preinitiation complex formation on its pro-apoptotic target promoters. Oncogene 34, 2461 (2014)

42. Feuerborn, A. et al. Dysfunctional p53 deletion mutants in cell lines derived from Hodgkin's lymphoma. Leuk. Lymphoma 47, 1932-1940 (2006). 
43. Mitsui, E. et al. Identification of ryuvidine as a KDM5A inhibitor. Sci. Rep. 9, 9952 (2019).

44. Blackford, A. N., Jackson, S. P. \& ATM, A. T. R. and DNA-PK: the trinity at the heart of the DNA damage response. Mol. Cell 66, 801-817 (2017).

45. Toledo, Luisl. et al. ATR prohibits replication catastrophe by preventing global exhaustion of RPA. Cell 155, 1088-1103 (2013)

46. Castedo, M. et al. Cell death by mitotic catastrophe: a molecular definition. Oncogene 23, 2825-2837 (2004).

47. De Toni, L. et al. Testicular cancer: genes, environment, hormones. Front Endocrinol. 10, 408 (2019).

48. Boccellino, M. et al. Testicular cancer from diagnosis to epigenetic factors. Oncotarget 8, 104654-104663 (2017).

49. Hanna, N. \& Einhorn, L. H. Testicular cancer: a reflection on 50 years of discovery. J. Clin. Oncol. 32, 3085-3092 (2014).

50. Raghavan, D. Testicular Cancer: Maintaining the High Cure Rate. (2003).

51. Chovanec, M. et al. Emerging prognostic biomarkers in testicular germ cell tumors: looking beyond established practice. Front. Oncol. 8, 571 (2018).

52. Cerami, E. et al. The cBio cancer genomics portal: an open platform for exploring multidimensional cancer genomics data. Cancer Discov. 2, 401 (2012).

53. $\mathrm{Fu}, \mathrm{X} . \mathrm{H}$. et al. KRAS G12V mutation is an adverse prognostic factor of chinese gastric cancer patients. J. Cancer 10, 821-828 (2019).

54. Renaud, S. et al. Prognostic value of the KRAS G12V mutation in 841 surgically resected Caucasian lung adenocarcinoma cases. Br. J. Cancer 113, 1206-1215 (2015).

55. Tang, Z. et al. GEPIA: a web server for cancer and normal gene expression profiling and interactive analyses. Nucleic Acids Res. 45, W98-W102 (2017).

56. Collins, F. S. Medical and societal consequences of the human genome project. N. Engl. J. Med. 341, 28-37 (1999).

57. Schwaederle, M. et al. Impact of precision medicine in diverse cancers: a metaanalysis of phase II clinical trials. J. Clin. Oncol. 33, 3817-3825 (2015).

58. Fontes Jardim, D. L. et al. Impact of a biomarker-based strategy on oncology drug development: a meta-analysis of clinical trials leading to FDA approval. J. Natl Cancer Inst. https://doi.org/10.1093/jnci/djv253 (2015).

59. Dumbrava, E. I. \& Meric-Bernstam, F. Personalized cancer therapy-leveraging a knowledge base for clinical decision-making. Cold Spring Harb. Mol. Case Stud. 4, a001578 (2018).

60. Liang, G. et al. Distinct localization of histone $\mathrm{H} 3$ acetylation and H3-K4 methylation to the transcription start sites in the human genome. Proc. Natl Acad. Sci. USA 101, 7357 (2004)

61. Pippa, S. et al. Small molecule inhibitors of KDM5 histone demethylases increase the radiosensitivity of breast cancer cells overexpressing JARID1B. Molecules 24, 1739 (2019).

62. Liu, H., Li, Y., Li, J., Liu, Y. \& Cui, B. H3K4me3 and Wdr82 are associated with tumor progression and a favorable prognosis in human colorectal cancer. Oncol. Lett. 16, 2125-2134 (2018).

63. Lewis, R. et al. Global reduction of H3K4me3 improves chemotherapeutic efficacy for pediatric ependymomas. Neoplasia 21, 505-515 (2019).

64. Ge, Z. et al. WDR5 high expression and its effect on tumorigenesis in leukemia. Oncotarget 7, 37740-37754 (2016).

65. Jiang, $\mathrm{H}$. et al. Role for Dpy-30 in ES cell-fate specification by regulation of H3K4 methylation within bivalent domains. Cell 144, 513-525 (2011).

66. van Nuland, R. et al. Quantitative dissection and stoichiometry determination of the human SET1/MLL histone methyltransferase complexes. Mol. Cell. Biol. 33, 2067 (2013)

67. Wang, P. et al. WDR5 modulates cell motility and morphology and controls nuclear changes induced by a 3D environment. Proc. Natl Acad. Sci. USA 115 8581 (2018).

68. $\mathrm{Li}, \mathrm{X}$. et al. The histone acetyltransferase MOF is a key regulator of the embryonic stem cell core transcriptional network. Cell Stem Cell 11, 163-178 (2012).
69. Neilsen, B. K. et al. WDR5 supports colon cancer cells by promoting methylation of H3K4 and suppressing DNA damage. BMC Cancer 18,673 (2018).

70. Yang, Z., Shah, K., Khodadadi-Jamayran, A. \& Jiang, H. Control of hematopoietic stem and progenitor cell function through epigenetic regulation of energy metabolism and genome integrity. Stem Cell Rep. 13, 61-75 (2019).

71. Howe, F. S., Fischl, H., Murray, S. C. \& Mellor, J. Is H3K4me3 instructive for transcription activation? BioEssays 39, e201600095 (2017).

72. Steward, M. M. et al. Molecular regulation of $\mathrm{H} 3 \mathrm{~K} 4$ trimethylation by ASH2L, a shared subunit of MLL complexes. Nat. Struct. Mol. Biol. 13, 852-854 (2006).

73. Clouaire, T. et al. Cfp1 integrates both CpG content and gene activity for accurate H3K4me3 deposition in embryonic stem cells. Genes Dev. 26, 1714-1728 (2012)

74. Clouaire, T., Webb, S. \& Bird, A. Cfp1 is required for gene expression-dependent H3K4 trimethylation and H3K9 acetylation in embryonic stem cells. Genome Biol. 15, 451 (2014).

75. Mei, L., Zhang, J., He, K. \& Zhang, J. Ataxia telangiectasia and Rad3-related inhibitors and cancer therapy: where we stand. J. Hematol. Oncol. 12, 43-43 (2019).

76. Zheng, A. et al. CRISPR/Cas9 genome-wide screening identifies KEAP1 as a sorafenib, lenvatinib, and regorafenib sensitivity gene in hepatocellular carcinoma. Oncotarget 10, 7058-7070 (2019).

77. Joung, J. et al. Genome-scale CRISPR-Cas9 knockout and transcriptional activation screening. Nat. Protoc. 12, 828 (2017).

78. Shalem, O. et al. Genome-scale CRISPR-Cas9 knockout screening in human cells. Science https://doi.org/10.1126/science.1247005 (2014).

79. Martin, M. Cutadapt removes adapter sequences from high-throughput sequencing reads. EMBnet.journal; Vol 17, No 1: Next Generation Sequencing Data AnalysisDO - https://doi.org/10.14806/ej.17.1.200 (2011).

80. Dobin, A. et al. STAR: ultrafast universal RNA-seq aligner. Bioinformatics 29 15-21 (2013).

81. Ritchie, M. E. et al. limma powers differential expression analyses for RNAsequencing and microarray studies. Nucleic Acids Res. 43, e47-e47 (2015).

82. Benjamini, Y. \& Hochberg, Y. Controlling the false discovery rate: a practical and powerful approach to multiple testing. J. R. Stat. Soc. Ser. B 57, 289-300 (1995).

83. Mi, H., Muruganujan, A. \& Thomas, P. D. PANTHER in 2013: modeling the evolution of gene function, and other gene attributes, in the context of phylogenetic trees. Nucleic Acids Res. 41, D377-D386 (2013).

84. Jordan, M., Schallhorn, A. \& Wurm, F. M. Transfecting mammalian cells: optimization of critical parameters affecting calcium-phosphate precipitate formation. Nucleic Acids Res. 24, 596-601 (1996).

85. Sanjana, N. E., Shalem, O. \& Zhang, F. Improved vectors and genome-wide libraries for CRISPR screening. Nat. Methods 11, 783-784 (2014).

86. Cho, Y.-W. et al. PTIP associates with MLL3- and MLL4-containing histone H3 lysine 4 methyltransferase complex. J. Biol. Chem. 282, 20395-20406 (2007)

87. Guan, B., Wang, T.-L. \& Shih, I.-M. ARID1A, a factor that promotes formation of SWI/SNF-mediated chromatin remodeling, is a tumor suppressor in gynecologic cancers. Cancer Res. 71, 6718-6727 (2011).

88. Klose, R. J. et al. The retinoblastoma binding protein RBP2 is an H3K4 demethylase. Cell 128, 889-900 (2007).

89. Kuhar, R. et al. Novel fluorescent genome editing reporters for monitoring DNA repair pathway utilization at endonuclease-induced breaks. Nucleic Acids Res. 42, e4-e4 (2014).

90. Dull, T. et al. A third-generation lentivirus vector with a conditional packaging system. J. Virol. 72, 8463-8471 (1998).

91. Li, S. et al. Disruption of OCT4 ubiquitination increases OCT4 protein stability and ASH2L-B-mediated H3K4 methylation promoting pluripotency acquisition. Stem Cell Rep. 11, 973-987 (2018). 